\title{
ß-Hydroxyimino Phosphorus Derivatives. An Efficient Tool in Organic Synthesis
}

\author{
Jesús M. de los Santos, Javier Vicario, Concepción Alonso and Francisco Palacios*
}

Departamento de Química Orgánica I, Facultad de Farmacia, Centro de Investigaciones y Estudios Avanzados "Lucio Lascaray", Universidad del País Vasco, Apartado 450, 01080 Vitoria-Gasteiz, Spain

\begin{abstract}
The purpose of this review article is to illustrate synthetic aspects of functionalized phosphorus derivatives containing an oximo moiety at the beta-position. First section will be focused on the synthesis of phosphine oxides, phosphonates or phosphonium salts containing an oxime group. The synthesis of these derivatives comprises the carbon-phosphorus single bond construction by reaction of haloximes with phosphorus derivatives, nucleophilic addition of phosphorus reagents to carbonyl compounds, or nucleophilic addition of phosphorus reagents to nitro olefins. This section will also concentrate on the most practical routes for the synthesis of the target compounds, through carbon-nitrogen double bond formation, which are as follows: condensation processes of carbonyl compounds and hydroxylamine derivatives or addition of hydroxylamines to allenes or alkynes. The preparative use of beta-oximo phosphorus derivatives as synthetic intermediates will be discussed in a second section, comprising olefination reaction, oxidation of oximes to nitrile oxides by reaction at the $\mathrm{C}-\mathrm{N}$ double bond of the oxime moiety, oxidation of these substrates to nitrosoalkenes, reduction to the corresponding hydroxylamines and some reactions at the hydroxyl group of the hydroxyimino moiety.
\end{abstract}

Keywords: $\beta$-Hydroxyimino phosphorus derivatives, $\alpha$-haloximes, nitro olefins, nitrile oxides, nitrosoalkenes.

\section{PREPARATION OF $\beta$-HYDROXYIMINO PHOSPHORUS DERIVATIVES}

Some general synthetic methods exist for the preparation of $\beta$ hydroxyimino phosphorus derivatives." This section will be focused on the synthesis of substituted phosphine oxide, phosphonate or phosphonium salts containing an oxime moiety at the $\beta$-position. Depending on the type of bond formed in the reaction, some strategies for the preparation of these derivatives can be highlighted (Scheme 1). Section 1.1 outlines their preparation through carbonphosphorus single bond construction by reaction of $\alpha$-haloximes with phosphorus derivatives (route $\mathrm{a}_{1}$ ), nucleophilic addition of phosphorus reagents to carbonyl compounds (route $\mathrm{a}_{2}$ ) or nucleophilic addition of phosphorus reagents to nitro olefins (route $a_{3}$ ). Section 1.2 will concentrate on the most practical routes for the synthesis of the target compounds, through carbon-nitrogen double bond formation, which are as follows: condensation processes (route $b_{1}$ ) and addition of hydroxylamines to allenes or alkynes (route $b_{2}$ ).

\subsection{Carbon-Phosphorus Single Bond Formation}

\subsubsection{Reaction of $\alpha$-Haloximes with Phosphines and Phosphites}

Alkylation of phosphines and phosphites constitutes an important entry to phosphorated oximes through C-P bond formation. Thus, reaction of oximes 2 , generated from condensation reaction of bromopyruvate $\mathbf{1}$ with $O$-methyl hydroxylamine, with triphenylphosphine $(\mathrm{R}=\mathrm{Ph})$, describes a general method through a C-P bond forming process for the preparation of oxime phosphonium salt $\mathbf{3 a}$.

*Address correspondence to this author at the Departamento de Química Orgánica I, Facultad de Farmacia, Centro de Investigaciones y Estudios Avanzados "Lucio Lascaray", Universidad del País Vasco, Apartado 450, 01080 Vitoria-Gasteiz, Spain; Tel: (+)34 945 013103; Fax: (+)34 945 013049;

E-mail: francisco.palacios@ehu.es

" These compounds could be named as $\beta$-hydroxyimino or $\beta$-oximo phosphorus derivatives if the phosphorated group is considered as the main group or $\alpha$-phosphorus substituted oximes if the oximo moiety is considered as the main function. In this account we use the former $\beta$-hydroxyimino or $\beta$-oximo phosphorus derivatives.
Similarly, $\beta$-phosphorylated oximes $\mathbf{3 b}$ or $\mathbf{3}$ can be obtained by means of Arbuzov reaction of oximes 2 with trimethylphosphite ( $R$ $=\mathrm{OMe}$ ) (Scheme 2) [1]. The alkylation of phosphines and phosphites with haloximes strategy has also been extended for the preparation of other substituted oximes derived from phosphonium salts [2] or phosphonates [3]. Similarly, when bromoacetophenone was used, functionalized oximes derived from phosphine oxides and phosphonates were obtained in good yields [4].

In a similar way, condensation reaction of 3-bromopyruvate 4 with hydroxylamine hydrochloride leads to $\alpha$-haloxime $\mathbf{5}$. Its protection with dihydropyrane affords $O$-THP oxime $\mathbf{6}$, which can be converted into oxime derived from phosphonium salt 7 in very good yield on reaction with triphenylphosphine (Scheme 3) [5].

The based-catalyzed reaction for the formation of oxime derived from phosphonium salt 9 might be explained by three paths: an attack by phosphorus atom on $\alpha$-carbon in the conjugate base of the oxime (path A), an initial attack of the base on the oxime carbon followed by displacement of bromine with $\mathrm{PPh}_{3}$ (path $\mathrm{B}$ ), or the preliminary replacement of bromine with base followed by displacement with $\mathrm{PPh}_{3}$ (path C), as shown in Scheme 4 [6]. Path C was ruled out by control experiments, which showed that (2phenyl-2-oxyiminoethyl)pyridinium bromide neither reacted with $\mathrm{PPh}_{3}$ nor catalyzed the reaction of 8 with $\mathrm{PPh}_{3}$, whereas a catalytic amount of pyridine lead to the exclusive formation of $\mathbf{9}$ under the identical conditions. Although there is no positive evidence, the catalytic reaction may be rationalized by path $\mathrm{A}$ or $\mathrm{B}$, which would have somewhat of an $S_{N} 1$ character since the transition states are stabilized by mesomeric electron release from the nearby anionic sites.

\subsubsection{Nucleophilic Addition of Phosphorus Reagents to Carbonyl Compounds}

Nucleophilic addition of phosphorus reagents to carbonyl compounds represents an easy strategy for the preparation of $\alpha$ hydroxy-phosphorylated compounds. This procedure has been applied to the keto-oxime $\mathbf{1 0}$ for the preparation of an $\alpha$-hydroxy- $\beta$ oximo phospine oxide derivative 11. In this way, addition of dimethyl phosphine oxide to keto-oxime $\mathbf{1 0}$ in the presence of ${ }^{t} \mathrm{BuOK}$ 


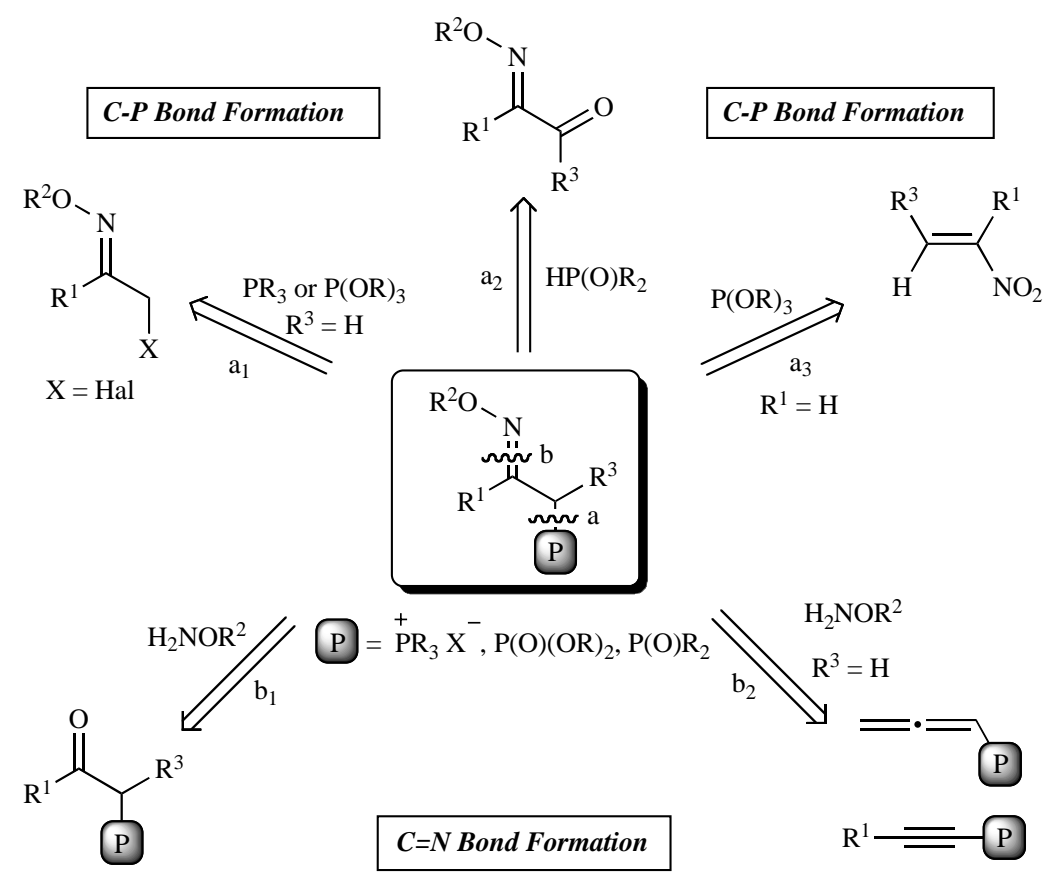

Scheme 1.

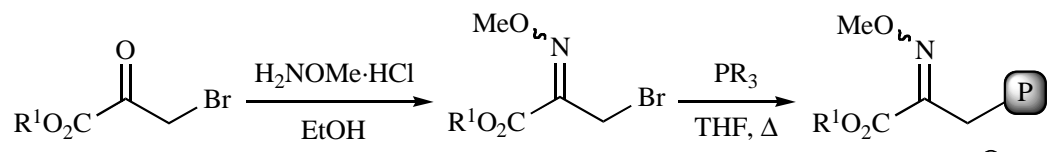

$$
\begin{aligned}
& 12 \\
& 2 \quad 3 \mathrm{R}^{1}=\mathrm{Et}, \mathrm{P}=\stackrel{\oplus}{\mathrm{P} P h_{3}} \stackrel{\ominus}{\mathrm{Br}} \\
& \text { 3b R } \mathrm{R}^{1}=\mathrm{Et}, \mathrm{P}=\mathrm{P}(\mathrm{O})(\mathrm{OMe})_{2} \\
& \text { 3c } \mathrm{R}^{1}=\mathrm{Me}, \mathrm{P}=\mathrm{P}(\mathrm{O})(\mathrm{OMe})_{2}
\end{aligned}
$$

Scheme 2.

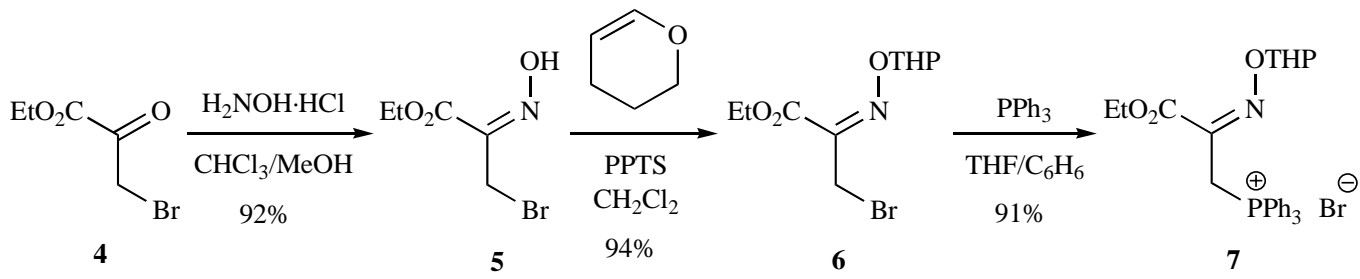

Scheme 3.

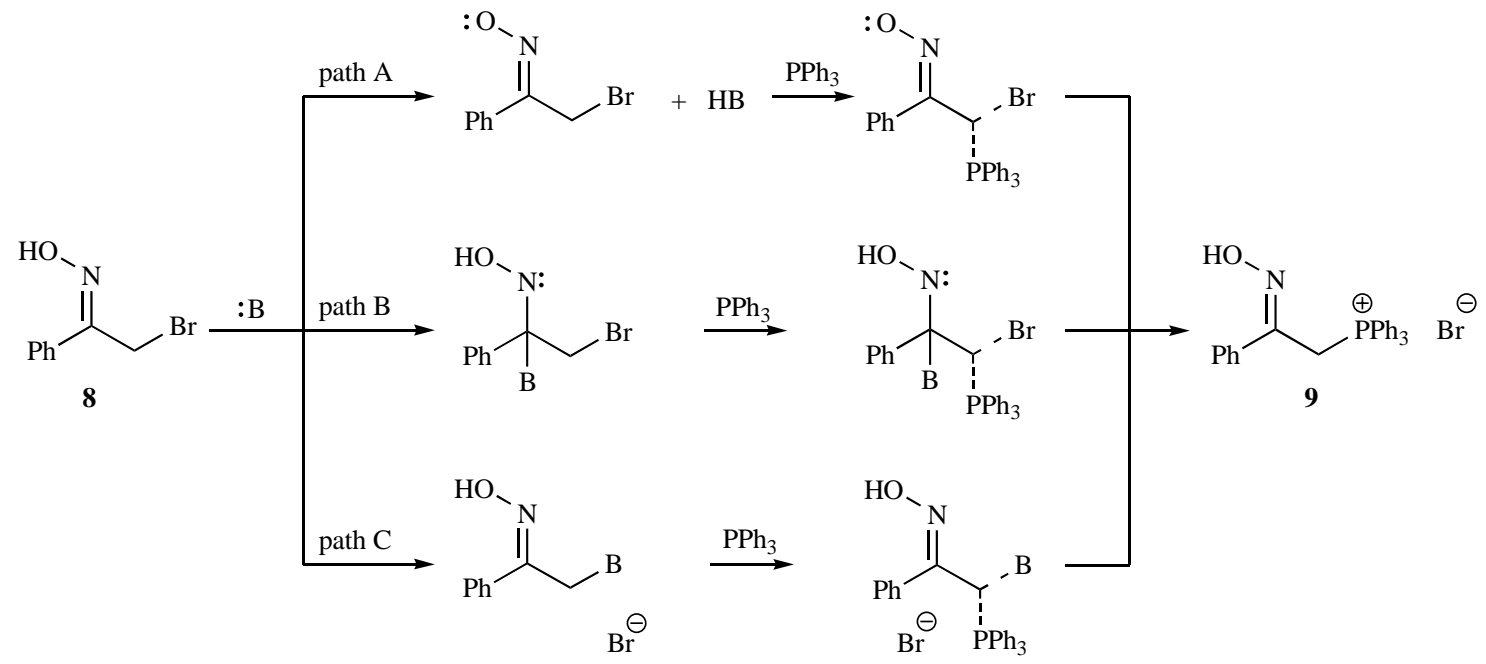

Scheme 4. 
leads to the potassium salt of phosphinylated oxime 11 (Scheme 5) [7].<smiles></smiles>

Scheme 5.

\subsubsection{Nucleophilic Addition of Phosphorus Reagents to Nitro Olefins}

Nitro olefins are useful intermediates in the synthesis of some biological active natural products. Due to the strong electron withdrawing properties of the nitro group, conjugated nitroalkenes are excellent Michael acceptors with a variety of nucleophiles. Several papers describe the addition of phosphorus nucleophiles to nitro olefins as Michael acceptors. Krueger et al. [8] reported that trimethylphosphite reacted with $\beta$-nitrostyrene $\mathbf{1 2}$ in tert-butyl alcohol to produce phosphorylated aldoxime 15 through $\mathrm{C}-\mathrm{P}$ bond formation. A reaction pathway which is consistent with the experimental and spectroscopic results is proposed in Scheme 6. The mechanism involves initial attack of trimethylphosphite at the $\alpha$ carbon of $\beta$-nitrostyrene 12, to form a zwitterion 13, which rearranges to the proposed cyclic intermediate 14. Methoxide ion attack on 14 affords the oxime 15. This compound was characterized unambiguously by x-ray crystallography [8a].

The above-mentioned study was followed by other authors [9], who reported the addition reaction of triethylphosphite to $\beta$ nitrostyrene 12. As reported in Scheme 7, reaction of nitroalkene 12 with 3.2 equivalents of triethylphosphite leads to a mixture of diphosphonate 16, nitrile 17 and phosphorylated oximes 18 and 19 as traces.

C-P Bond creation with the formation of a $\beta$-oxime phosphonate derived from sugars has also been observed in the reaction of $\beta$-nitro sugar 20 with trimethylphosphite. In this case, a mixture of
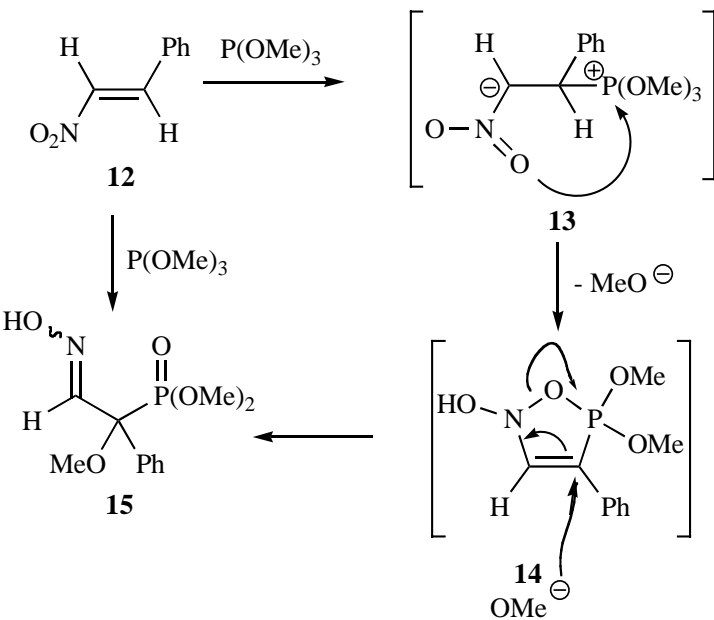

Scheme 6.

alkene $\mathbf{2 1}$ and phosphorylated aldoxime $\mathbf{2 2}$ were obtained in very low yield (Scheme 8) [10].

Phosphorylated haloximes can be prepared from the reaction of conjugated nitroalkenes with diethyl phosphite. In such a way, treatment of conjugated nitroalkenes $\mathbf{2 3}$ with diethyl phosphite in the presence of a base such as sodium hydride and subsequent addition of $\mathbf{H C l}$ gives haloximes $\mathbf{2 4}$ in very good yield (Scheme 9) [11].

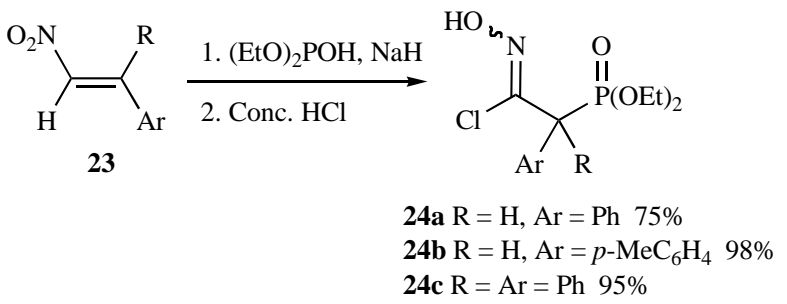

Scheme 9.

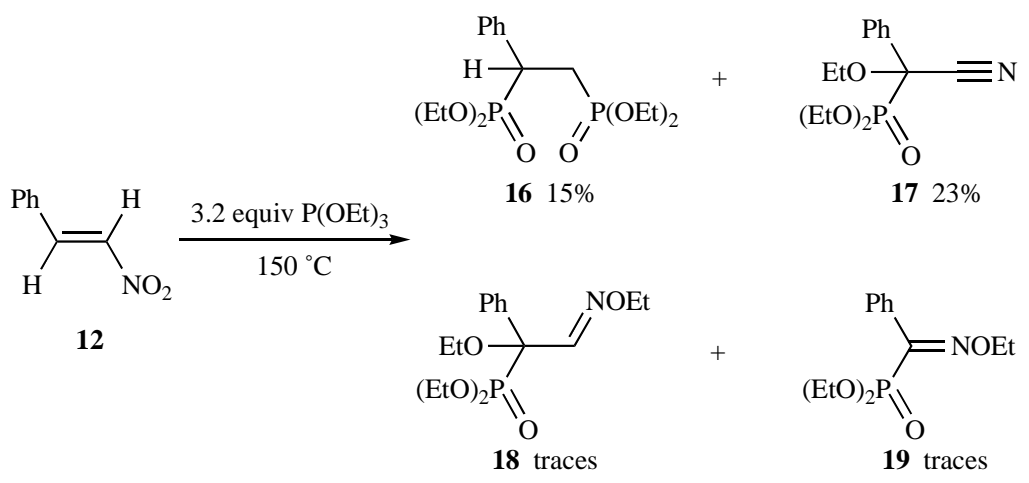

Scheme 7.

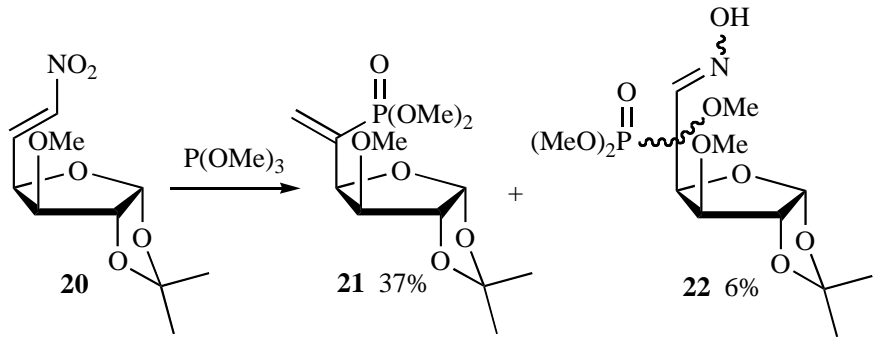

Scheme 8. 


\subsection{Carbon-Nitrogen Double Bond Formation}

\subsubsection{Condensation Reaction}

Condensation reaction of a $\beta$-keto phosphorus substituted compounds with hydroxylamines to give aldoximes or ketoximes, represents a simple route for the preparation of $\beta$-oximo phosphorus derivatives via a carbon-nitrogen double bond-forming process. This is one of the most common synthetic ways for the preparation of oximes. Arbuzov reaction of bromoacetaldehyde diethyl acetal (25) with triethylphosphite affords phosphorylated acetal 26 with a $\mathrm{C}-\mathrm{P}$ bond formation process (Scheme 10) [12]. Deacetalization under acidic conditions and condensation with hydroxylamine hydrochloride in the presence of a base give aldoxime $\mathbf{2 8}$ in good yield.

Similarly, nucleophilic addition of hydroxylamine to the keto carbonyl group of diethyl $\beta$-ketopropylphosphonate $(\mathbf{2 9 a})(\mathrm{R}=\mathrm{OEt}$, $\mathrm{R}^{1}=\mathrm{Me}$ ) in aqueous solution around $\mathrm{pH}=7$ leads to $\beta$-oximo phosphonate 31a (Scheme 11) [13]. Using ${ }^{1} \mathrm{H}$ and ${ }^{31} \mathrm{P}$ NMR spectroscopy, during the reaction, it was possible to detect the carbinolamine 30a resulting from addition of hydroxylamine to the keto carbonyl group, the syn- and anti-isomers of the oxime of the diester 31a and the syn- and anti-isomers of the oxime of the monoester 32. Under these conditions oxime 31a undergo phosphate ester hydrolysis which appear to involve internal assistance by the $\mathrm{OH}$ group of the oxime, since no hydrolysis was detected for the $O$ methyloxime of 29a. This assistance may involve nucleophilic addition to phosphorus atom by the $\mathrm{OH}$ oxygen to form a pentacovalent intermediate. Following this strategy, $\beta$-oximo phosphine oxides 31b $(\mathrm{R}=\mathrm{Ph})$ have been synthesized by our group using triethylamine as the base (Scheme 11) [14].

Some phosphorylated oximes have been tested as $N$-methyl-Daspartate (NMDA) receptor antagonists. Since it appeared that the binding potency and relatively good bioavailability of $\mathbf{3 3}$ could be related to the $\beta$-ketophosphonic acid functionality, Whitten et al.
[15] sought to modify the ketone with similar, less readily enolizable groups. Thus, a mixture of syn- and anti-oximes or their ethers 34 were synthesized through condensation reaction of readily available hydroxylamines with $(R)$-4-oxo-5-phosphononorvaline $(\mathbf{3 3})$ by standard procedures (Scheme 12).

Alkylation of the anion derived from diethyl methylphosphonate (35) with methyl iodide followed by addition of dimethylformamide affords a general method for the preparation of 1formylalkanephosphonate 36 [16], which could be converted to the phosphorylated oxime $\mathbf{3 7}$ by condensation reaction of aldehyde $\mathbf{3 6}$ with hydroxylamine (Scheme 13) [17]. Related phosphinyl aldoximes have been obtained in $86 \%$ yield by using the same conditions when starting from methyl diphenylphosphine oxide [18].

This approach has been also used for the preparation of $\beta$ oximo phosphine oxides 40a $(\mathrm{R}=\mathrm{Ph})$ and $\beta$-oximo phosphonates 40b $(\mathrm{R}=\mathrm{OEt})$ containing a fluoroalkyl substituent [19]. Hence, metallation of alkyl diphenylphosphine oxides 38a or alkylphosphonates 38b with LDA and subsequent treatment with fluorinated esters affords fluorine substituted $\beta$-ketophosphine oxides 39a or $\beta$ ketophosphonates 39b, respectively (Scheme 14). The condensation of ketones $\mathbf{3 9}$ with hydroxylamine hydrochloride in the presence of pyridine gives fluorinated oximes $40 \mathrm{a}$ or $40 \mathrm{~b}$.

This method developed for the preparation of $\beta$-ketophosphonates using anions derived from alkyl phosphonates has been expanded to cyclic ketophosphonates, and thus, cyclic phosphorylated oximes by condensation reaction with hydroxylamines were reported. The diester 42 resulting from $\mathrm{NiCl}_{2}$-catalyzed Arbuzov reaction of diethyl methylphosphonate and ethyl iodobenzoate 41, reacts with 3 equivalents of potassium tert-butoxide in diethyl ether effecting cyclization to 43. The corresponding phosphorylated oximes 44 resulted from oximation reaction of ketone 43 with the appropriate hydroxylamine (Scheme 15) [20].

Similarly, condensation of phosphonate anions derived from $\mathbf{4 5}$ with diesters can be used for the preparation of 3-phosphonopyruvate

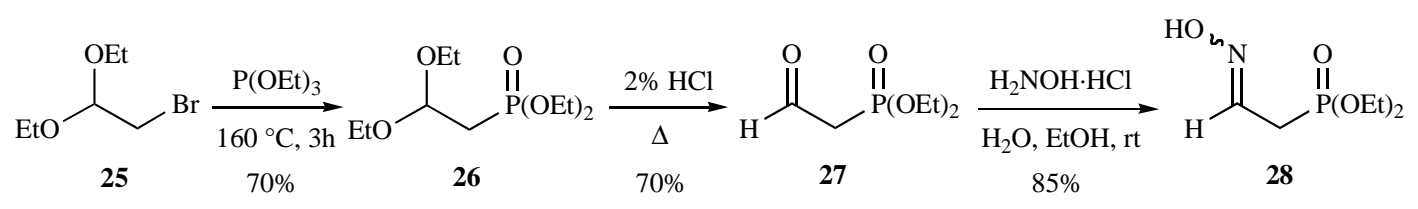

Scheme 10.

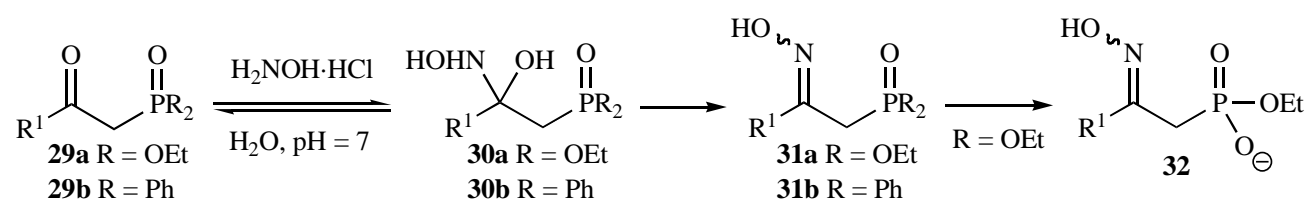

Scheme 11.

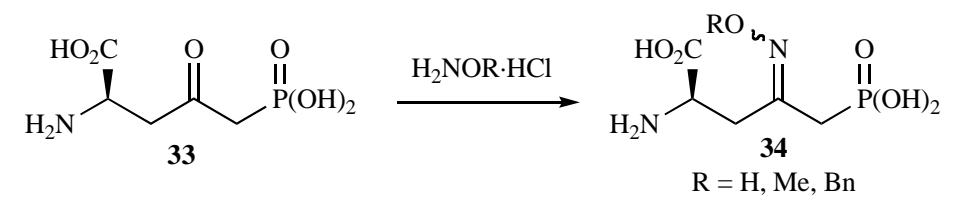

Scheme 12.

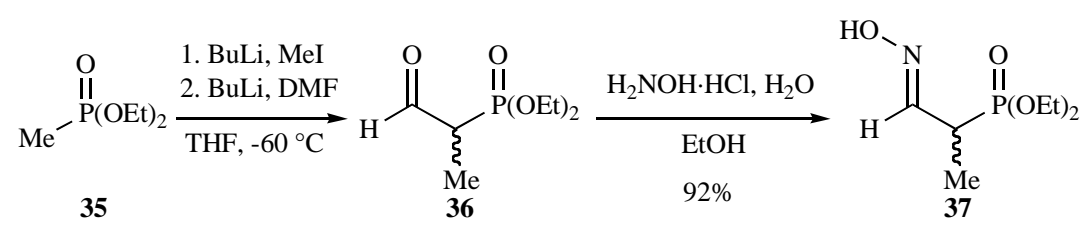

Scheme 13. 


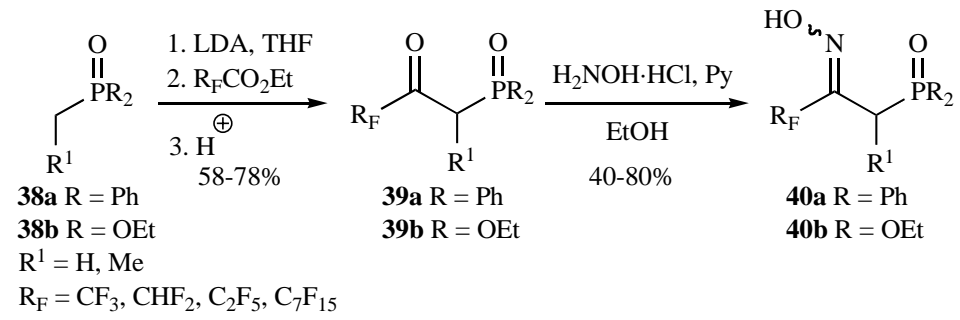

Scheme 14.<smiles>CCOC(=O)c1ccccc1I</smiles>
41

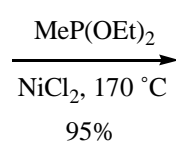
$95 \%$<smiles>CCOC(=O)c1ccccc1P(C)(=O)OCC</smiles>

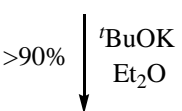<smiles>[R6]N=C1CP(=O)(OCC)c2ccccc21</smiles>

44a $\mathrm{R}=\mathrm{H} 88 \%$

44b $\mathrm{R}=\mathrm{Me} 90 \%$<smiles>CCOP1(=O)CC(=O)c2ccccc21</smiles>

43
Scheme 15.

derivatives 46 (Scheme 16) [21]. Oximation of these derivatives 46 affords functionalized oximes $\mathbf{4 7}$ in good yields.

$\beta$-Oximo phosphine oxides $\mathbf{5 0}$ can be obtained by $\mathrm{C}-\mathrm{N}$ double bond formation through condensation reaction of hydroxylamine with $\beta$-keto phosphine oxides 49, previously prepared on treatment of stannyloxiranes 48 with lithium diphenylphosphine (Scheme 17) [22].

Oximes containing a phospholene ring can be prepared by quaternization reaction of trivalent $P$-bromophospholene 51. Thus, reaction of bromophospholene $\mathbf{5 1}$ with $\alpha$-chloroketone $\mathbf{5 2}$ afforded functionalized phospholene $P$-oxide 53, which after condensation reaction with hydroxylamine hydrochloride give phosphorylated oxime 54 (Scheme 18) [23].

Other oximes containing a phospholene ring have been prepared through a condensation reaction of ethyl formate with the anion derived from phospholene $P$-oxide 55 [24]. The corresponding aldehyde obtained $\mathbf{5 6}$ is condensed with hydroxylamine hydrochloride affording oxime phospholene 57 (Scheme 19).

Minami et al. [25] have reported a synthetic methodology for the preparation of $\alpha$-formylvinylphosphonates $\mathbf{6 0}$, precursors of oximes 61. Allylic alcohols 58, prepared by trapping anions derived from vinylphosphonates with aldehydes and ketones, can react in acidic conditions to afford vinylphosphonates $\mathbf{6 0}$ in very good yields. This reaction probably proceeds via a mechanism which included attack of water on an allylic carbocation $\mathbf{5 9}$ stabilized by the oxygen atom. The $\mathrm{C}-\mathrm{N}$ double bond formation in $\mathbf{6 1}$ takes place by treatment of $\mathbf{6 0}$ with hydroxylamine and pyridine in ethanol under reflux (Scheme 20).

\subsubsection{Nucleophilic Addition of Hydroxylamines to Allenyl or Alkynyl Derivatives}

A different approach can also be applied for the preparation of phosphorylated oximes though $\mathrm{C}-\mathrm{N}$ double bond formation. This strategy involves conjugative addition of hydroxylamine to the

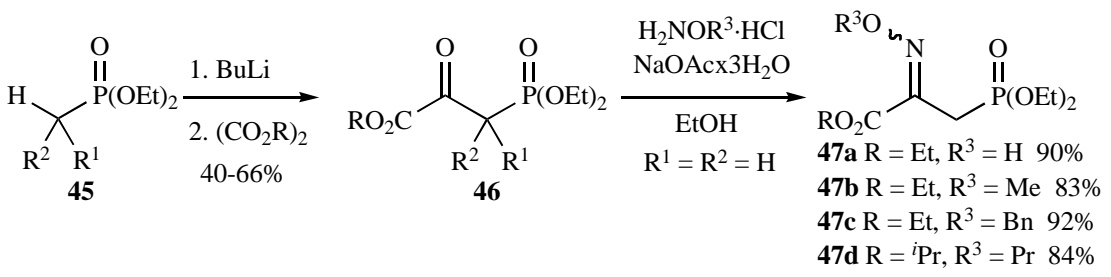

Scheme 16.

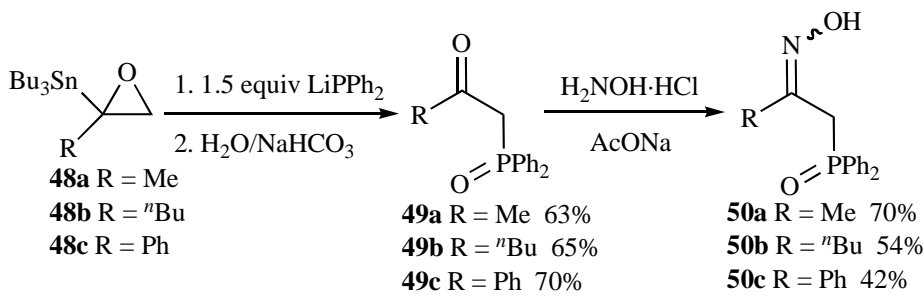

Scheme 17.

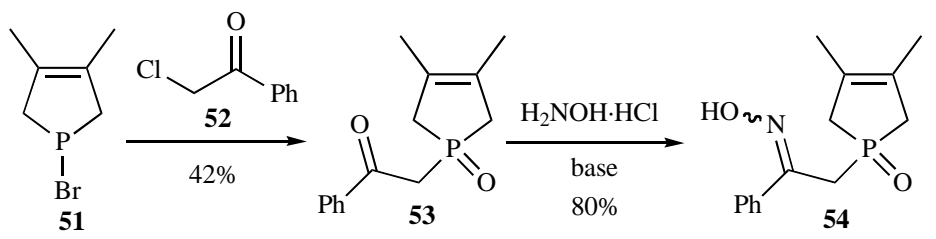

Scheme 18. 


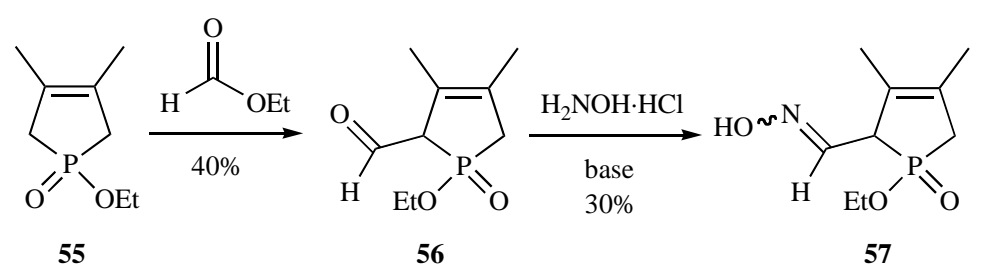

Scheme 19.

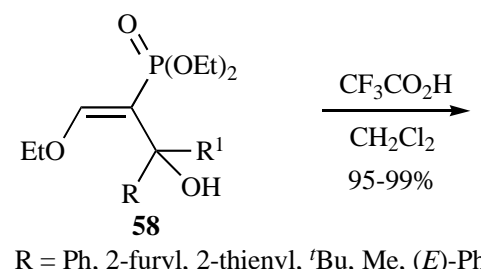

$\mathrm{R}=\mathrm{Ph}$, 2-furyl, 2-thienyl, ${ }^{t} \mathrm{Bu}, \mathrm{Me},(E)-\mathrm{PhCH}=\mathrm{CH}$

$\mathrm{R}^{1}=\mathrm{H}, \mathrm{Me}, \mathrm{Ph}$
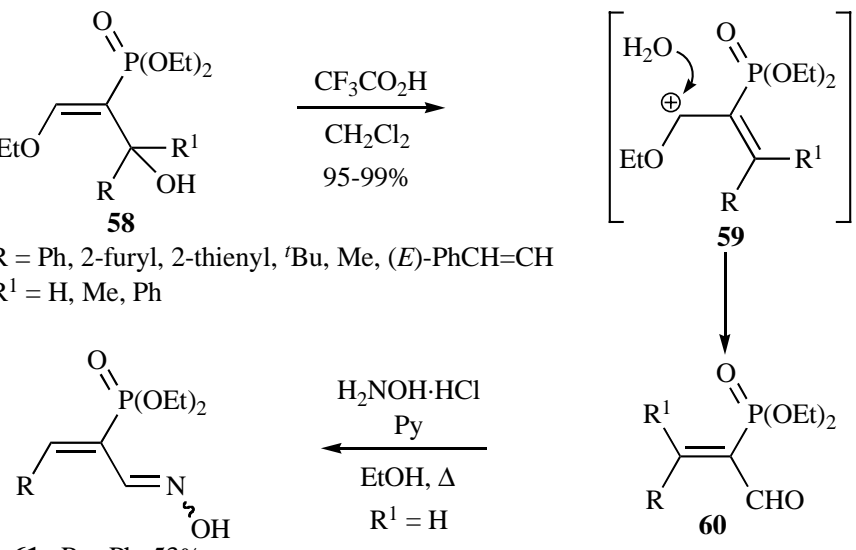

$$
\begin{aligned}
& \text { 61a } R=P h \quad 53 \% \\
& \text { 61b } R=2 \text {-furyl } 60 \% \\
& \text { 61c } R=2 \text {-thienyl } 69 \% \\
& \text { 61d } R={ }^{t} B u \quad 61 \%
\end{aligned}
$$

\section{Scheme 20.}

acetylenic C-C-triple bond of tetraethyl ethynyldiphosphonate $\mathbf{6 2}$, and subsequent tautomerization of the $N$-hydroxyenamine 63 [26]. Through this procedure, oxime bisphosphonate 64 can be synthesized in $85 \%$ yield (Scheme 21).

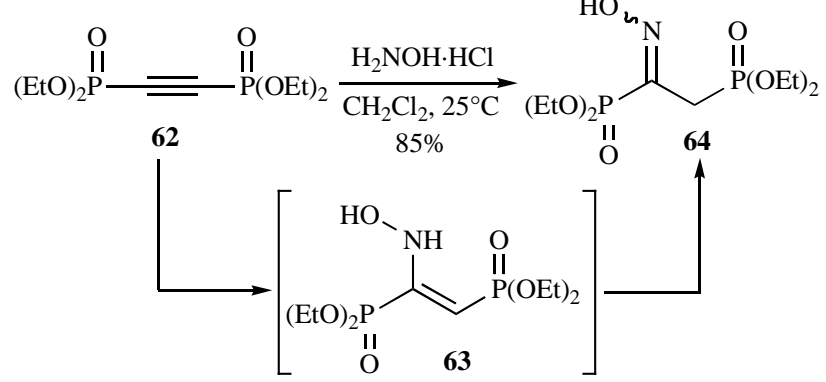

Scheme 21.

In a similar way, nucleophilic addition of unsubstituted hydroxylamine $\left(\mathrm{R}^{3}=\mathrm{H}\right), O$-methylhydroxylamine $\left(\mathrm{R}^{3}=\mathrm{Me}\right)$ or $O$ silyl substituted hydroxylamines $\left(\mathrm{R}^{3}=\mathrm{SiMe}_{3}, \mathrm{SiMe}_{2}{ }^{t} \mathrm{Bu}\right)$ to allenyl phosphine oxides 65a $(\mathrm{R}=\mathrm{Ph})$ or phosphonates 65b $(\mathrm{R}=\mathrm{OEt})$ represents an easy procedure for the preparation of $\beta$-oximo phosphine oxides 67a $(\mathrm{R}=\mathrm{Ph})$ or $\beta$-oximo phosphonates 67b $(\mathrm{R}=$
OEt), via functionalized enamines 66, in good yields (Scheme 22) [27].

\subsection{Ring Opening of 1,2,5-Oxazaphospholines}

Umani-Ronchi et al. [2c] report the reaction between nitrile oxides 68 and phosphonium ylides 69 as a useful method for the preparation of 1,2,5-oxazaphosph(V)ol-2-ines 70. The successful transformation of $\mathbf{7 0}$ into the corresponding 2-hydroxyimino phosphonium salts 71 involves the ring opening of $\mathbf{7 0}$ by $\mathrm{P}-\mathrm{O}$ bond cleavage by the action of hydrobromic [2c] or hydrochloric acid [28] (Scheme 23). In a similar way, oxime ethers phosphonium salts 72 can be obtained by ring opening of 1,2,5oxazaphospholines $\mathbf{7 0}$ on treatment with iodomethane [28] (Scheme 23). The use of nitrile oxides for the synthesis of such heterocycles 70, and thus these $\beta$-oximo phosphonium salts $\mathbf{7 1}$ and 72, offers a more limited route of synthesis, when compared with the Arbuzov reaction of $\alpha$-haloximes and phosphines [2] (see Scheme 2). This is because of the limited availability of nitrile oxides $\mathbf{6 8}$, which usually are less easily obtained than $\alpha$-haloximes. Moreover, the reaction requires the use of phosphonium ylides 69 instead of simple phosphines.

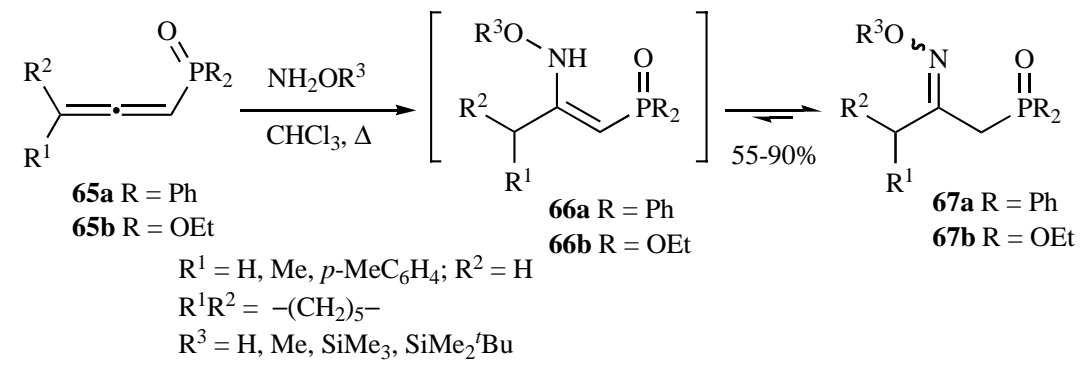

Scheme 22. 


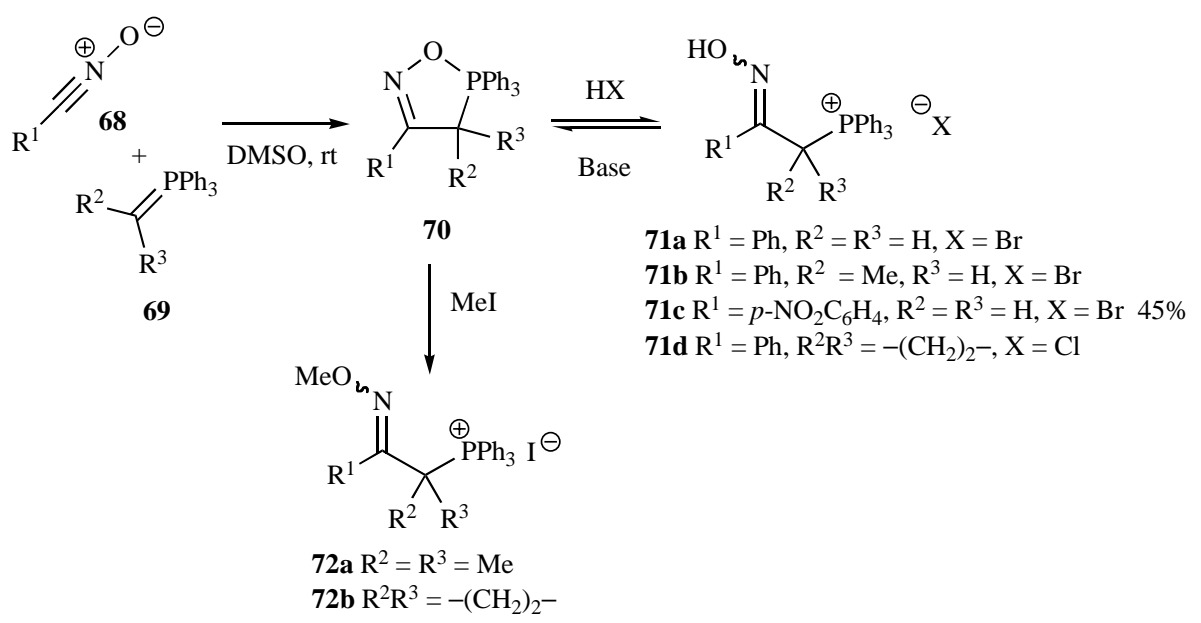

Scheme 23.

\section{REACTIVITY. PREPARATIVE USE OF $\beta$-HYDROXYI- MINO PHOSPHORUS DERIVATIVES AS SYNTHETIC INTERMEDIATES}

$\beta$-Hydroxyimino phosphorus derivatives are bifunctional compounds and contain an oxime moiety and a phosphorated group linked by a carbon atom. Characteristic reactions of the oxime function such as the oxidation of these substrates to nitrosoalkenes and nitrile oxides, reduction to the corresponding hydroxylamines and some reactions at the hydroxyl group of the hydroxyimino moiety has been reported, while the presence of phosphorus functional groups confers an additional preparative interest to these substrates because they can be used for the construction of selective $\mathrm{C}-\mathrm{C}$ double bonds by means of the Wittig reactions or related processes [29] (Scheme 24).

\subsection{Olefination Reaction}

One of the most representative examples of the reactivity of $\alpha$ carbanions derived from some phosphorus derivatives entails the $\mathrm{C}-\mathrm{C}$ double bond forming process, through Wittig reaction [29] or related processes with carbonyl compounds. For carbon-carbon double bond construction, not only phosphonium salts (Wittig reaction) but also phosphine oxide derivatives (Horner reaction) or phosphonates (Horner-Wadsworth-Emmons reaction) are very useful reagents. For this reason, $\beta$-oximo phosphorus compounds can be excellent starting materials for the selective preparation of $\alpha, \beta$-unsaturated oximes. Moreover, this is a very useful method for the preparation of 1-azabuta-1,3-dienes, important building blocks for the preparation of six-membered nitrogen containing heterocycles. For example, Boger et al. have described the preparation of $\mathrm{N}$ -

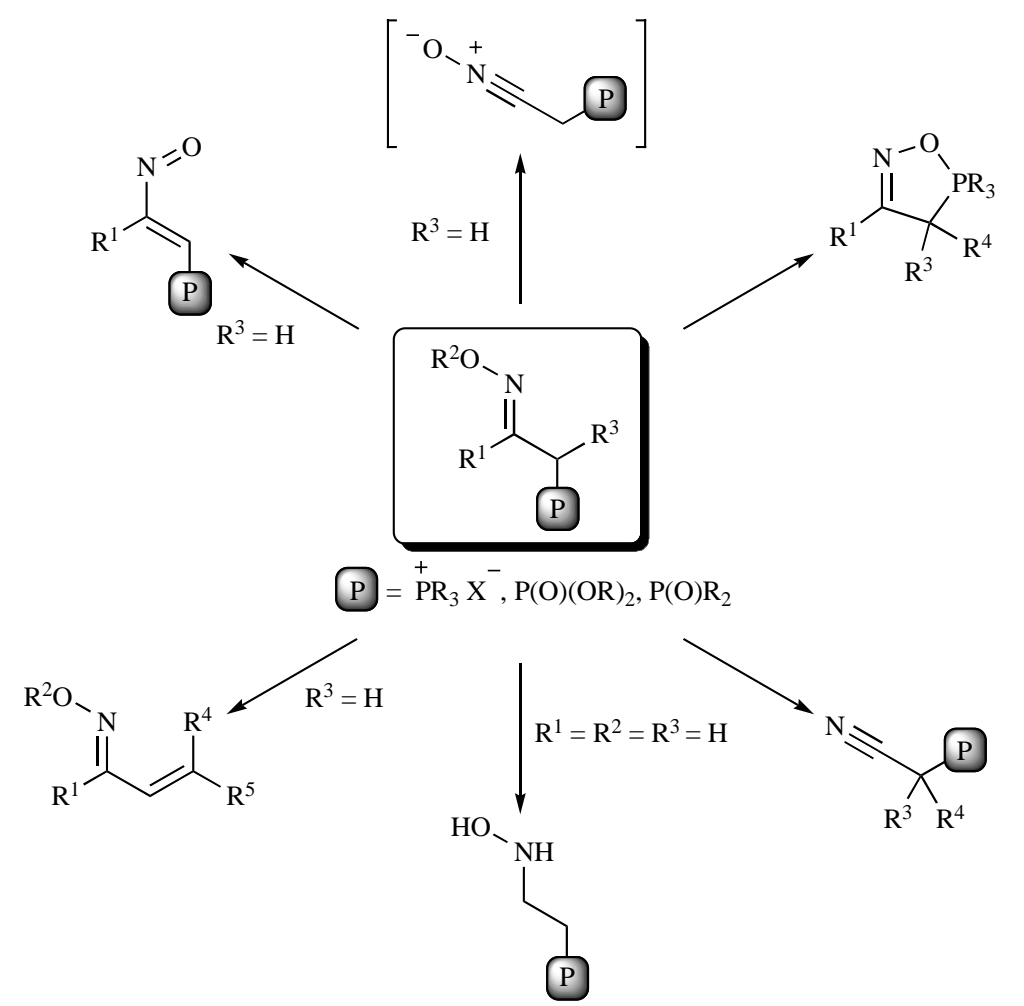

Scheme 24. 


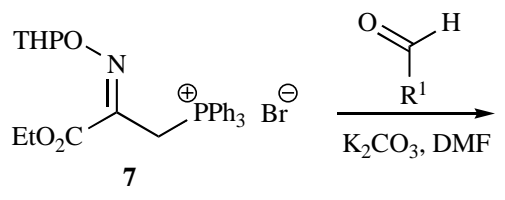<smiles>[R20]SI</smiles><smiles>[R]C=CC(=NC)C(=O)OCC</smiles>
$\frac{\mathrm{R}^{2} \mathrm{SOCl}, \mathrm{Et}_{3} \mathrm{~N}}{\mathrm{CCl}_{4}}$

75a $\mathrm{R}^{1}=\mathrm{R}^{2}=\mathrm{Ph} 69 \%$

75b R $\mathrm{R}^{1}=\mathrm{Ph}, \mathrm{R}^{2}=\mathrm{Me} 64 \%$

75c $\mathrm{R}^{1}=\mathrm{Hex}, \mathrm{R}^{2}=\mathrm{Ph} 64 \%$

75d $R^{1}=$ Hex, $R^{2}=$ Me $59 \%$

75e $\mathrm{R}^{1}=\mathrm{Me}, \mathrm{R}^{2}=\mathrm{Ph} 45 \%$

$\mathbf{7 5 f} \mathrm{R}^{1}=\mathrm{R}^{2}=\mathrm{Me} 45 \%$

$75 \mathrm{~g} \mathrm{R}^{1}=o-\mathrm{ROC}_{6} \mathrm{H}_{4}, \mathrm{R}^{2}=$ Me $53-86 \%$<smiles>[R]C=CC(=NOc1ccccc1)C(=O)OCC</smiles>

73a $\mathrm{R}^{1}=\mathrm{Ph} 94 \%$

73b $\mathrm{R}^{1}=\mathrm{Hex} 89 \%$

73c $\mathrm{R}^{1}=$ Me $72 \%$

73d R ${ }^{1}=o-\mathrm{ROC}_{6} \mathrm{H}_{4} \quad 83-94 \%$

$\mathrm{AcOH} / \mathrm{H}_{2} \mathrm{O} / \mathrm{THF}$<smiles>[R]C=CC(=NO)C(=O)OCC</smiles>

74a $\mathrm{R}^{1}=\mathrm{Ph} 82 \%$

74b R $\mathrm{R}^{1}=$ Hex $55 \%$

74c $\mathrm{R}^{1}=\mathrm{Me} 72 \%$

74d $\mathrm{R}^{1}=o-\mathrm{ROC}_{6} \mathrm{H}_{4} \quad 67-97 \%$

Scheme 25.

sulfonyl-1-azabuta-1,3-dienes $\mathbf{7 5}$, based on the use of the stabilized Wittig reagent containing an oximo group 7 , and their $4 \pi$ participation in inter [5, 30] and intramolecular [31] [4+2] cycloaddition reactions. 4-Substituted $N$-sulfonyl-1-azabuta-1,3-dienes 75 are prepared through Wittig reaction of the stabilized phosphorane generated in situ from the phosphonium salt $\mathbf{7}$ with aldehydes, followed by acid-catalyzed removal of the tetrahydropyranyl (THP) group, $O$ phenylsulfinyl or $O$-methylsulfinyl formation, and subsequent in situ homolytic rearrangement to provide 75 (Scheme 25). 1-Azadienes, prepared through Wittig olefination reaction of $\beta$-oximo phosphonium salts, have been also used as building blocks for the preparation of indole-3-piruvic acid oxime ethers by Heck cyclization [32].
Our group [27] reported an efficient method for the preparation of $\alpha, \beta$-unsaturated oximes through olefination reaction, starting from oximes containing phosphorated functional groups. Consequently, $\beta$-oximo phosphine oxides 67a $(\mathrm{R}=\mathrm{Ph})$ can be suitable precursor for the homologation of oximes into their vinylogous compounds. Oximes 67a $(\mathrm{R}=\mathrm{Ph})$ are treated with a base such as methyl lithium, followed by addition of aromatic, heteroaromatic and aliphatic aldehydes and ketones leading to 1-azadienes $\mathbf{7 6}$ with high $E$-stereoselectivity of the carbon-carbon double bond, isolated as a mixture of syn- and anti-isomers, and in good yields (Scheme 26). This olefination reaction is not restricted to $\beta$-oximo phosphine oxides 67a $(\mathrm{R}=\mathrm{Ph})$ since oximes derived from phosphonates $67 \mathbf{b}$ $(\mathrm{R}=\mathrm{OEt})$ can also be used in this approach.
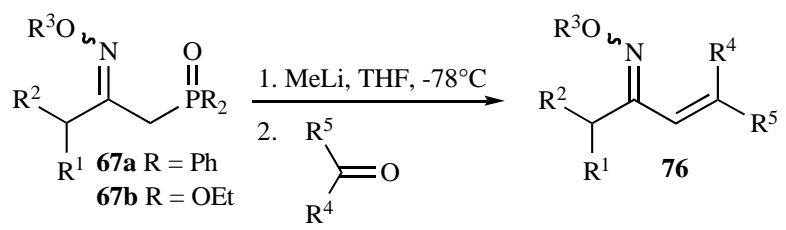

\begin{tabular}{|c|c|c|c|c|c|c|}
\hline Comp. & $\mathbf{R}^{1}$ & $\mathbf{R}^{2}$ & $\mathbf{R}^{3}$ & $\mathbf{R}^{4}$ & $\mathbf{R}^{5}$ & Yield (\%) \\
\hline $76 a$ & $\mathrm{H}$ & $\mathrm{H}$ & $\mathrm{H}$ & $\mathrm{H}$ & ${ }^{i} \mathrm{Bu}$ & 81 \\
\hline $76 \mathrm{~b}$ & $\mathrm{H}$ & $\mathrm{H}$ & $\mathrm{H}$ & $\mathrm{H}$ & 2- $\mathrm{C}_{5} \mathrm{H}_{4} \mathrm{~N}$ & 72 \\
\hline $76 c$ & $\mathrm{H}$ & $\mathrm{H}$ & $\mathrm{H}$ & $\mathrm{Ph}$ & $\mathrm{Ph}$ & 80 \\
\hline 76d & $\mathrm{H}$ & $\mathrm{H}$ & $\mathrm{H}$ & \multicolumn{2}{|c|}{$-\left(\mathrm{CH}_{2}\right)_{5}-$} & 74 \\
\hline $76 e$ & $\mathrm{H}$ & $\mathrm{Me}$ & $\mathrm{H}$ & $\mathrm{H}$ & $p-\mathrm{MeC}_{6} \mathrm{H}_{4}$ & 88 \\
\hline $76 f$ & $\mathrm{H}$ & $\mathrm{Me}$ & $\mathrm{H}$ & $\mathrm{H}$ & ${ }^{i} \mathrm{Bu}$ & 77 \\
\hline $76 \mathrm{~g}$ & $\mathrm{H}$ & $\mathrm{H}$ & $\mathrm{SiMe}_{3}{ }^{t} \mathrm{Bu}$ & $\mathrm{H}$ & $p-\mathrm{MeC}_{6} \mathrm{H}_{4}$ & 80 \\
\hline $76 \mathrm{~h}$ & $\mathrm{H}$ & $\mathrm{Me}$ & $\mathrm{SiMe}_{3}{ }^{t} \mathrm{Bu}$ & $\mathrm{H}$ & $p-\mathrm{MeC}_{6} \mathrm{H}_{4}$ & 71 \\
\hline $76 i$ & \multicolumn{2}{|c|}{$-\left(\mathrm{CH}_{2}\right)_{5^{-}}$} & $\mathrm{SiMe}_{3}{ }^{t} \mathrm{Bu}$ & $\mathrm{H}$ & $p-\mathrm{MeC}_{6} \mathrm{H}_{4}$ & 80 \\
\hline $76 j$ & $\mathrm{H}$ & $\mathrm{H}$ & $\mathrm{Me}$ & $\mathrm{H}$ & $p-\mathrm{MeOC}_{6} \mathrm{H}_{4}$ & 75 \\
\hline $76 \mathrm{k}$ & $\mathrm{H}$ & $\mathrm{Me}$ & $\mathrm{Me}$ & $\mathrm{H}$ & ${ }^{i} \mathrm{Bu}$ & 65 \\
\hline
\end{tabular}


There has been considerable interest in vinyl glycines as antibiotics, enzyme inhibitors and synthetic intermediates. The $\beta$ aminophosphonium salt 77, a vinyl glycine synthon derived from serine, is tedious to prepare and has to be used as its free acid to avoid $\beta$-elimination. Oxime phosphonium salt 3a $\left(\mathrm{P}=\mathrm{PPh}_{3}{ }^{+} \mathrm{Br}^{-}\right)$ provide advantages as an amino acid synthon. Reaction of phosphorane derived from salt 3a, generated from the treatment of 3a with a base, with aldehydes gave the required 1-azabuta-1,3-dienes $\mathbf{7 8}$ with yields ranging from 50 to $99 \%$ (Scheme 27). ${ }^{n}$ Butyl lithium was the initial base chosen for the generation of phosphorane derived from 3a. However, owing the partially stabilized nature of this phosphorane, it was reasoned that a weaker base would suffice. The preferred choice was potassium carbonate in DMF, which requires no special precautions and has provided excellent yields. To increase the versatility of this approach, reactions of ketones was required. Hence, Horner-Wadsworth-Emmons (H-W-E) olefination reaction of phosphorylated oxime $3 \mathbf{c}\left(\mathrm{P}=\mathrm{P}(\mathrm{O})(\mathrm{OMe})_{2}\right)$ with sodium hydride and the corresponding ketone leads to the final azadienes 78 in $24-54 \%$ yield. Finally, the vinyl glycine derivatives 79 were obtained in good yields by reduction of $\alpha, \beta$-unsaturated oximes 78 with zinc in formic acid (Scheme 27) [1].

An illustration of the olefination reaction of a phosphorylated oxime as the key step in the synthesis of natural products is present in the total synthesis of radiosumin $\mathbf{8 4}$, a strong trypsin inhibitor from the blue-green alga plectonema radiosum (Scheme 28) [3a,33]. This structurally intriguing dipeptide $\mathbf{8 4}$ is composed of<smiles>[R]OC(=O)C(C[PbH])NC(C)=O</smiles><smiles></smiles>

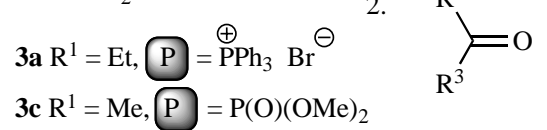<smiles>[R]C([R])=O</smiles>

\begin{tabular}{|c|c|c|c|c|c|c|c|}
\hline 3 & $\mathbf{R}^{1}$ & 78 & $\mathbf{R}^{2}$ & $\mathbf{R}^{3}$ & Yield (\%) & 79 & Yield (\%) \\
\hline $3 \mathbf{a}$ & Et & $78 a$ & $\mathrm{H}$ & Et & 50 & 79a & 84 \\
\hline $3 \mathbf{a}$ & Et & $78 \mathrm{~b}$ & $\mathrm{H}$ & ${ }^{i} \operatorname{Pr}$ & 99 & $79 \mathrm{~b}$ & 94 \\
\hline $3 \mathbf{a}$ & Et & $78 \mathrm{c}$ & $\mathrm{H}$ & $\mathrm{Ph}$ & 98 & $79 \mathrm{c}$ & 65 \\
\hline $3 \mathbf{a}$ & Et & 78d & $\mathrm{H}$ & $p-\mathrm{CF}_{3} \mathrm{C}_{6} \mathrm{H}_{4}$ & 99 & & \\
\hline $3 \mathrm{c}$ & $\mathrm{Me}$ & $78 \mathrm{e}$ & Et & Et & 24 & $79 e$ & 99 \\
\hline $3 \mathrm{c}$ & $\mathrm{Me}$ & $78 f$ & \multicolumn{2}{|c|}{$-\left(\mathrm{CH}_{2}\right)_{5}-$} & 36 & $79 f$ & 49 \\
\hline $3 \mathrm{c}$ & $\mathrm{Me}$ & $78 \mathrm{~g}$ & \multicolumn{2}{|c|}{$-\left(\mathrm{CH}_{2}\right)_{2} \mathrm{~S}\left(\mathrm{CH}_{2}\right)_{2}-$} & 54 & $79 \mathrm{~g}$ & 37 \\
\hline
\end{tabular}

Scheme 27.

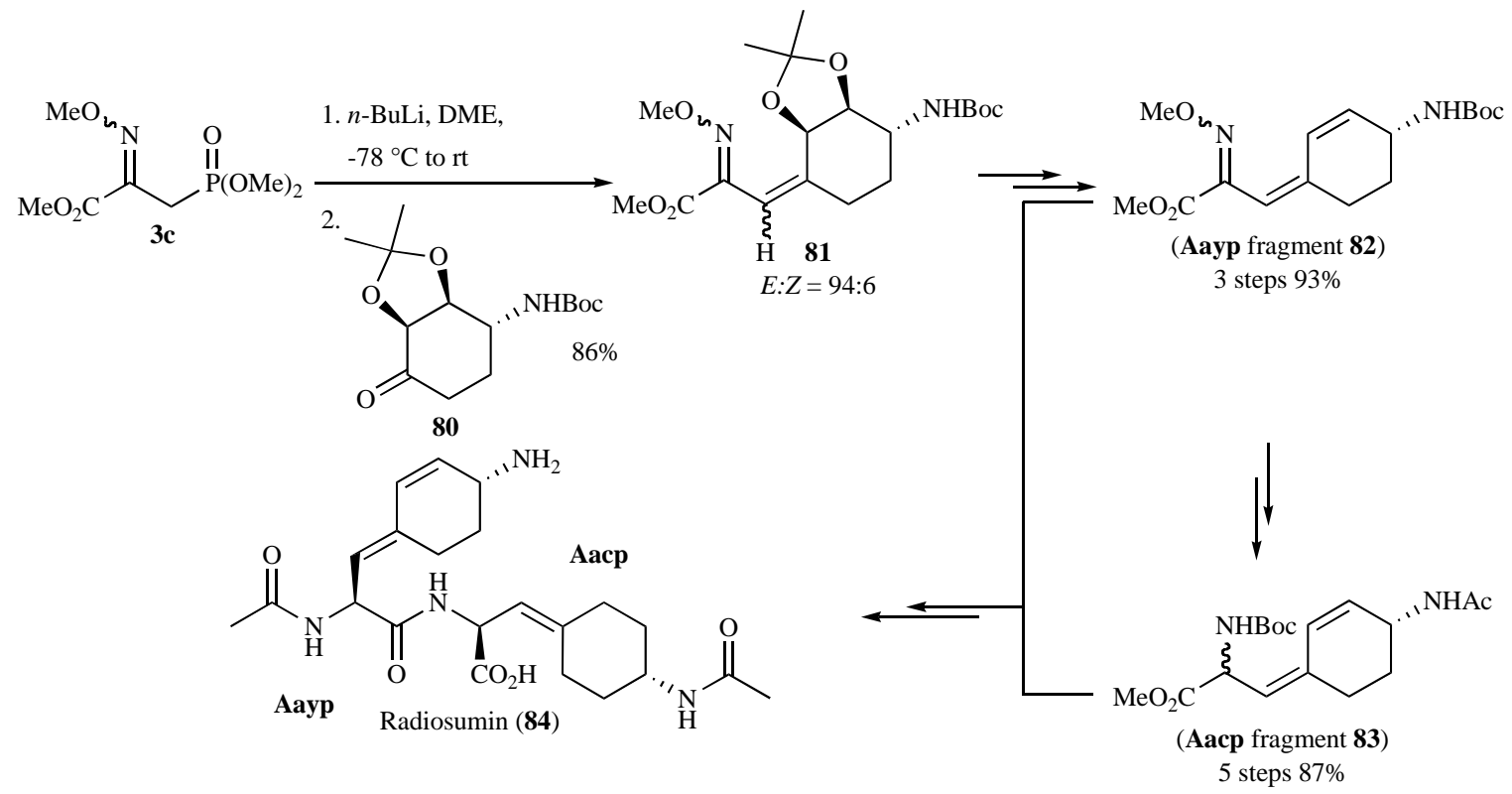


two unusual, novel $\alpha$-amino acids: 2-amino-3-(4-amino-2cyclohexen-1-ylidene)propionic acid (Aayp) (82) and 2-amino-3(4-amino-2-cyclohexylidene)propionic acid (Aacp) (83). Stereoselective Horner-Wadsworth-Emmons reaction of oxime 3c with aminocyclitol ketone $\mathbf{8 0}$ furnished one of the building blocks $\mathbf{8 1}$ for the construction of Aayp derivative 82. The other one, Aacp derivative $\mathbf{8 3}$ needed for the preparation of radiosumin $\mathbf{8 4}$, was prepared in five steps starting from the common intermediate $\mathbf{8 2}$.

Furthermore, the high efficiency of this protocol has been also applied to the total synthesis of naturally occurring amino acid 2,6diaminopimelic acid (DAP) (87) found in both bacteria and higher plants (Scheme 29) [34]. Condensation of the aldehyde 85, with the stabilized phosphorane three carbon synthon derived from 3a, affords the corresponding unsaturated oxime ester 86. This compound serve as a versatile intermediate to a variety of DAP analogues, since one can selectively reduce the oxime and the olefinic moieties.

\subsection{Reactions at the $\mathrm{C}-\mathrm{N}$ Double Bond}

\subsubsection{Oxime Reductions}

Through a simple oxime-amine reduction, fluorine containing $\beta$-amino phosphine oxides or phosphonates may be prepared in satisfactory yields [19]. For this goal, treatment of fluorine containing $p$-toluenesulfonyl oxime 88a derived from phosphine oxides or $p$-toluenesulfonyl oxime $\mathbf{8 8 b}$ derived from phosphonates with $\mathrm{NaBH}_{4}$ at low temperature gives fluorine containing $\beta$-amino phosphine oxide 89a or phosphonates $89 \mathbf{b}, \mathbf{c}$ in a regioselective fashion [19] (Scheme 30). In a similar way, $\beta$-aminophosphonate derivatives [35] have been prepared starting from phosphorylacetaldehyde oximes, by means of an oxime-hydroxylamine reduction employing the pyridine-borane complex [36].

\subsubsection{Oxidation Reactions}

\subsubsection{Nitrile Oxide Formation}

Nitrile oxides have been much more frequently used in organic synthesis, especially in the elaboration of complex molecules, than any other 1,3-dipoles [37]. The importance of nitrile oxide is based on its high reactivity toward a wide range of olefins, both electronpoor and -rich types, forming isoxazolines which are flexible building blocks through their ability to function as masked forms of $\beta$ hydroxyketones [38] and $\gamma$-amino alcohols [39], after the $\mathrm{N}-\mathrm{O}$ bond cleavage. Phosphorus functionalized nitrile oxides undergo regioselective 1,3-dipolar cycloadditions to olefins or acetylenes to furnish good yields of 2-isoxazolines or isoxazoles bearing a phosphorus substituent. For example, Tsuge et al. reported the first synthesis of phosphorus functionalized nitrile oxide and its cycloaddition with a variety of olefins. Nitrile oxide $\mathbf{9 1}$ is successfully accessible by the bromination of $\mathbf{2 8}$ with NBS ( $N$-bromosuccinimide) followed by dehydrobromination of haloxime $\mathbf{9 0}$ with triethylamine. This nitrile oxide 91 has been trapped as cycloadduct with a variety of olefinic dipolarophiles giving the corresponding isoxazolines $\mathbf{9 2}$ as single regioisomers and in good yield (Scheme 31) [12d,e]. Cycloaddition of phosphorus functionalized nitrile oxide $\mathbf{9 1}$ to acetylenic alcohols affords compounds 93. This approach has been reported in the synthesis of $E$-isomers of furanone derivatives which are essential part of the framework of furanone natural products such as geiparvarin [40] (Scheme 31). Other dipolarophiles such as allyl [41] and homoallyl alcohols [42] or $\alpha, \beta$-unsaturated esters [43] have been used for the cycloaddition reaction to 91 to give terpene, pyridine or furanone derivatives, respectively. Likewise, isoxazolinephosphonates and isoxazolephosphonates substituted at 4- and 5-positions have been obtained by cycloaddition of olefins and acetylenes to 91 [12c].

This method developed for the cycloaddition reaction of nitrile oxides with dipolarophiles was subsequently expanded to the preparation of $\alpha$-alkoxycarbonyl- $\beta$-diketones by Jones et al. [12b]. Phosphorylated isoxazole derivative 96, resulting from the cycloaddition of nitrile oxide $\mathbf{9 1}$ with enamines $\mathbf{9 5}$, was used as starting material for the construction of C-C double bonds when they were treated under basic conditions with a variety of aldehydes and ketones (benzaldehyde, propanone, cyclohexanone, but-2-enal and (E)-2methylbut-2-enal) to afford the 3-alkenylisoxazoles 97 (Scheme 32). Treatment of 97 with hexacarbonylmolybdenum in moist acetonitrile gives efficient access to $\alpha$-alkoxycarbonyl- $\beta$-diketones 98 in excellent yields. Early work by Warren et al. [18] shows the viability to performing the cycloaddition of nitrile oxide, olefination<smiles>CCOC(=O)C(=O)OCC=O</smiles><smiles>CCCOC(=O)[C@H](N)CC=C/C(=N\OC)C(=O)OCC</smiles>

86

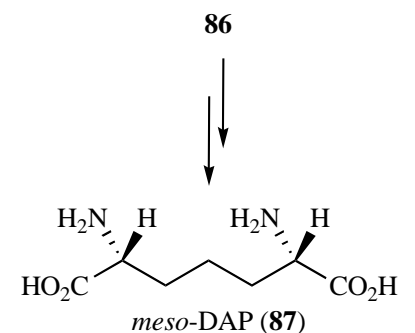

Scheme 29.

$$
\begin{aligned}
& \mathrm{TsO} \\
& \begin{array}{l}
\mathbf{8 8 a} \mathrm{R}=\mathrm{Ph} \\
\mathbf{8 8 b} \mathrm{R}=\mathrm{OEt}
\end{array} \\
& \underset{\text { THF, }-30{ }^{\circ} \mathrm{C}}{\stackrel{\mathrm{NaBH}_{4}}{\longrightarrow}}
\end{aligned}
$$$$
\overbrace{\mathrm{P}(\mathrm{OR})_{2}}^{\mathrm{NH}_{2}}
$$$$
\text { 89a } \mathrm{R}_{\mathrm{F}}=\mathrm{CF}_{3}, \mathrm{R}=\mathrm{Ph} 74 \%
$$$$
\text { 89b } \mathrm{R}_{\mathrm{F}}=\mathrm{CF}_{3}, \mathrm{R}=\mathrm{OEt} 72 \%
$$$$
\text { 89c } \mathrm{R}_{\mathrm{F}}=\mathrm{C}_{2} \mathrm{~F}_{5}, \mathrm{R}=\text { OEt } 45 \%
$$ 


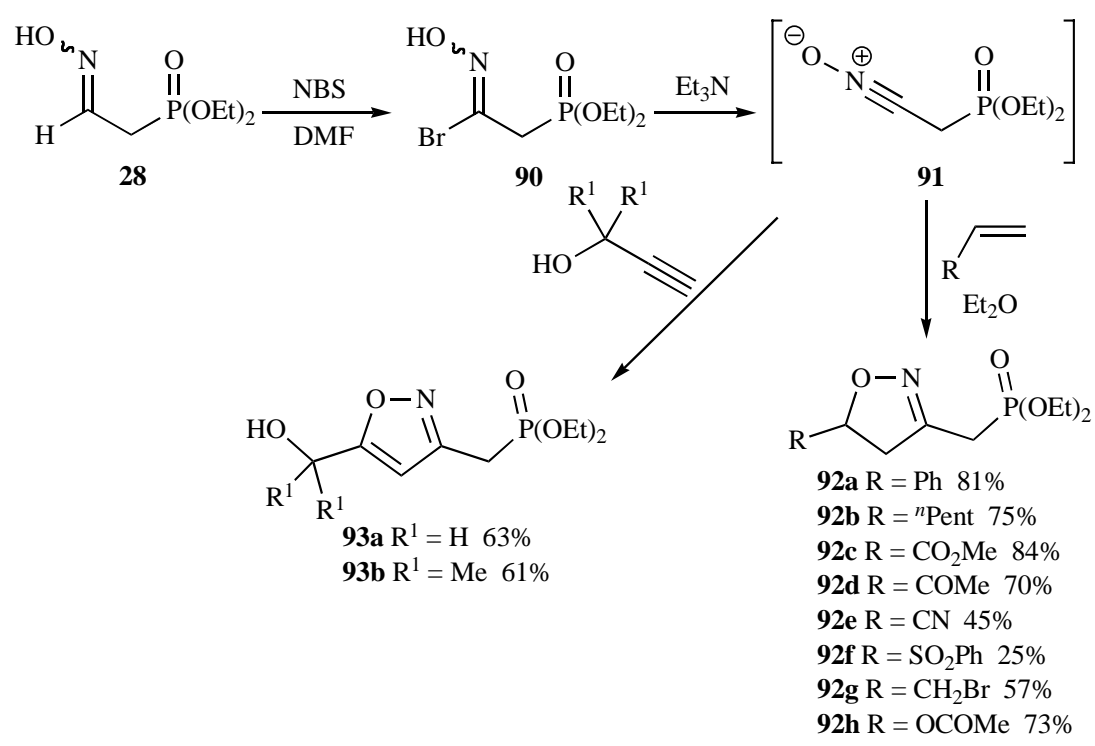

Scheme 31.

reaction and cleavage with $\mathrm{Mo}(\mathrm{CO})_{6}$ of isoxazole ring, for the regiospecific synthesis of derived leukotriene analogues using phosphine oxides.

The synthetic utility of this approach has been recently demonstrated in the preparation of $1 \beta$-methylcarbapenem $\mathbf{1 0 0}$ which showed markedly antibacterial activity as well as high stability to DHP-I against pseudomonas aeruginosa isolates and advanced pharmacokinetic profiles in rat and dog than those of meropenem (Scheme 33) [12a].

Recently, phosphonated dihydroisoxazole nucleosides have been prepared via 1,3-dipolar cycloaddition reaction of nitrile oxides with the corresponding vinyl nucleobases for antiviral studies [44]. This synthesis has been performed in a one-step process as shown in Scheme 34. The nitrile oxide 91, derived in situ from aldoxime $\mathbf{2 8}$ by treatment with NBS under basic conditions, was added to the vinyl nucleobases to give the racemic nucleosides 101 . This reaction showed a complete regioselectivity obtaining the 5-isomer as an exclusive product.
The synthetic value of nitrile oxide cycloaddition is now growing as shown in its wide applications to natural product synthesis. For example, Carreira et al. [17,45] reported the stereoselective syntheses of epothilones A and B via magnesium-mediated hydroxyl-directed nitrile oxide cycloadditions with allyl alcohols, inspired by the work of Kanemasa [46]. In this regard, the cycloadditions of the versatile oxime $\mathbf{3 7}$ with chiral allyl alcohols is the key to the Carreira's strategy. Oxidation of $\mathbf{3 7}$ to nitrile oxide $\mathbf{1 0 3}$ was followed by highly diastereoselective cycloaddition with an allyl alcohol 104, containing and additional sterocenter, to furnish $\mathbf{1 0 5}$ as a single syn-diastereomer at the isoxazoline oxygen (Scheme 35). Furthermore, these authors have applied the diastereoselective nitrile oxide cycloaddition of homoallylic alcohols in the synthesis of polyketide building blocks [47].

\subsubsection{Nitrosoalkene Formation}

Nitrosoalkenes are functionalized nitroso derivatives, and the presence of an adjacent double bond in conjugation with the nitroso moiety introduces new reactivity centers in these substrates and

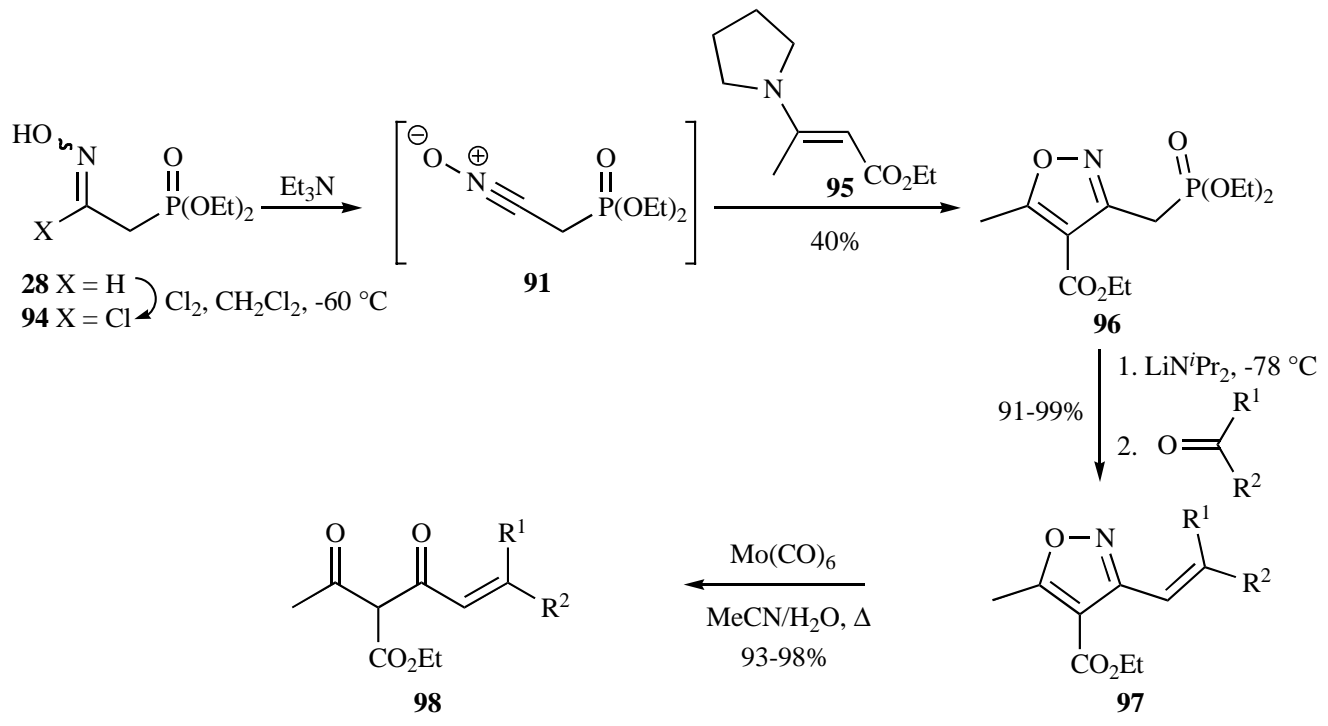

Scheme 32. 
<smiles>C#CC(=O)OCC</smiles>

Scheme 33.<smiles>[B]C#C[B]C1CC(C[P+](=O)OCC)=NO1</smiles>
28 NHAc<smiles></smiles>

Scheme 34.<smiles>[Y19]C(/C=N/O)[PH](=O)OCC</smiles>

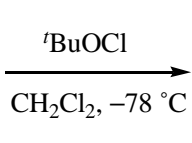

37

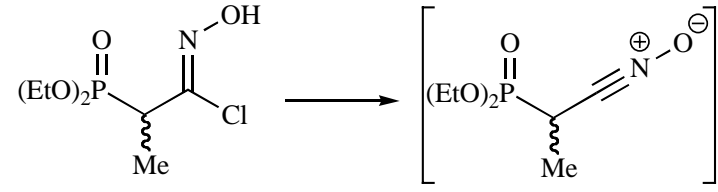

102
103

3.3 equiv ${ }^{i} \mathrm{PrOH}$ 3.0 equiv $\mathrm{EtMgBr}$ $\mathrm{CH}_{2} \mathrm{Cl}_{2}$
Epothilones A and $\mathrm{B} \longleftarrow \longleftarrow$
Scheme 35.

then increases the synthetic value of these compounds. Therefore, the usefulness of nitrosoalkenes [48] as conjugate addition acceptors [49], coupled with the easy conversion of the nitroso group into other functionalities, such as oximes and ketones [50], or their ability to act as dienes in hetero-Diels-Alder reactions for the preparation of 1,2-oxazine derivatives [51], have been reported. The synthesis of nitrosoalkenes containing a phosphorus substituent at $C-4$ has been scarcely explored. Only one example of the preparation of these systems has been recently reported by our group [52]. As outlined in Scheme 36, for the preparation of phosphorylated nitrosoalkenes $\mathbf{1 0 8}$ the required bromooximes $\mathbf{1 0 7}$ are easily accessible from reaction of functionalized oximes $\mathbf{1 0 6}$ with an excess of base and subsequent addition of bromine. Nitrosoalkenes 108 have been prepared in almost quantitative yield through base-mediated dehydrohalogenation of $\alpha$-bromooximes 107. These functionalized nitrosoalkenes are useful Michael acceptors and thus, conjugate addition of nucleophilic reagents such as ammonia, primary and secondary amines or optically active amino esters furnish $\alpha$ aminophosphine oxides $(\mathrm{R}=\mathrm{Ph})$ and phosphonates $(\mathrm{R}=\mathrm{OEt}) \mathbf{1 0 9}$ in a highly regioselective fashion (Scheme 36) [52]. More recently, these nitrosoalkenes $\mathbf{1 0 8}$ have been used for the preparation of fivemembered nitrogen containing heterocycles such as $\mathrm{N}$ hydroxypyrrole derivatives 110, through conjugate addition of enamines at the terminal carbon atom of the heterodiene 108, ring closure (formally a [3+2] dipolar cycloaddition), and elimination of the pyrrolidine residue (Scheme 36) [53]. The synthesis of similar $\mathrm{N}$-hydroxypyrroles is also reported by other authors via conjugate 
addition of enolates derived from ketones to phosphorylated $\alpha$ chlorooximes [54].

\subsection{Reactions at the OH Group of the Oxime Moiety}

\subsubsection{Cyclization Reactions}

Some reports [2b,c,28a] describes the preparation of oxazaphospholine intermediates $\mathbf{7 0}$ by treatment of oxime phosphonium salts 71 with a base. These oxazaphospholines are readily converted, on pyrolysis at $100-150{ }^{\circ} \mathrm{C}$, into $2 H$-azirines 111 by an initial $\mathrm{P}-\mathrm{C}$ bond cleavage [55], subsequent loss of triphenylphosphine oxide and ring-contraction (Scheme 37).

A convenient synthesis of phosphono-substituted heterocyclic compounds has been recently reported through vinylphosphonates via condensation-intramolecular 1,4-addition sequence [25]. $\alpha$ Formylvinylphosphonates $\mathbf{6 0}$ are treated with hydroxylamine hy- drochloride and pyridine in ethanol under reflux to afford 4phosphono isoxazoles 112. Treatment of the independently prepared oxime 113 with pyridine in ethanol under reflux afforded the isoxazole 112a in quantitative yield (Scheme 38). This result demonstrates that the oxime $\mathbf{1 1 3}$ clearly underwent the 5-endo-trigonal cyclization to give the isoxazole $\mathbf{1 1 2 a}$.

\subsubsection{Dehydratation of Oximes}

Acetic anhydride-mediated dehydration of oximes can be applied to aldoxime $\mathbf{1 5}$ for the preparation of substituted phosphonate carbonitrile 115a. The formation of nitrile 115a apparently preceded by acylation of the starting aldoxime $\mathbf{1 5}$ with formation of the intermediate acetate 114, and subsequent elimination of acetic acid (Scheme 39) [8c]. A similar behaviour has been observed by our group starting from $O$-tosyl aldoximes and diethyl cyanomethylphosphonate 115b was obtained [56].

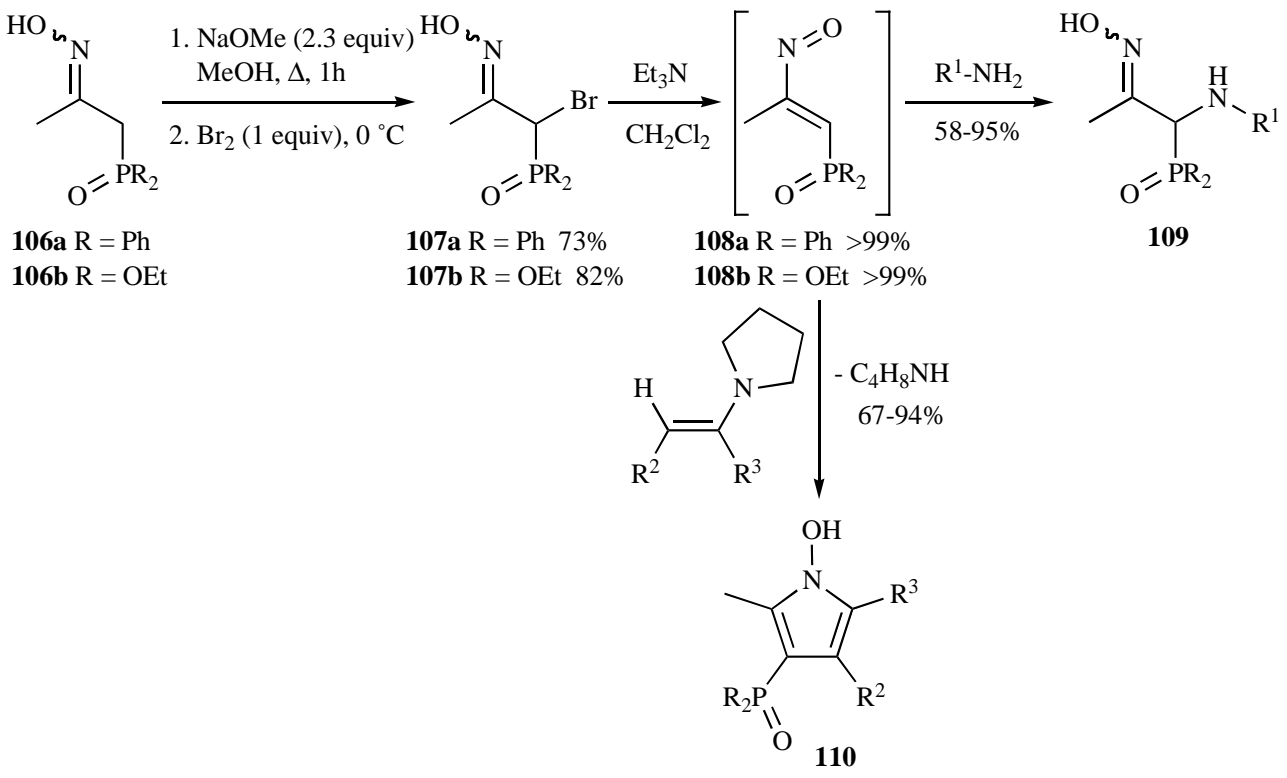

Scheme 36.

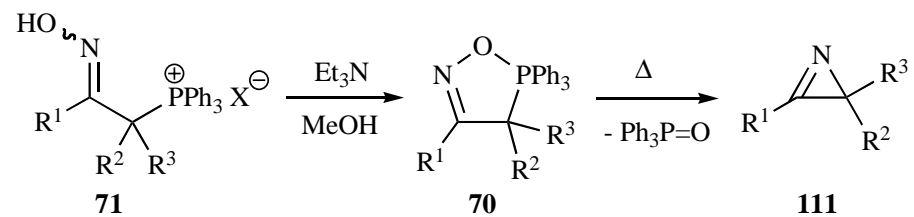

Scheme 37.<smiles>[R]C([R])=C(C=O)[P+](=O)OC</smiles>

60<smiles>CCOC(=O)C(C=NC)=C(C)C</smiles>

$113 \stackrel{\mathrm{OH}}{\mathrm{O}}$
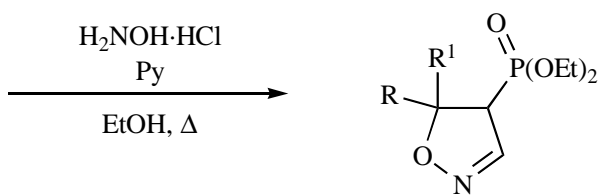

112a $R=R^{1}=$ Me $76 \%$

112b $R=R^{1}=P h \quad 74 \%$<smiles>CCOC(=O)C1C=NOC1(C)C</smiles>

112a

Scheme 38. 


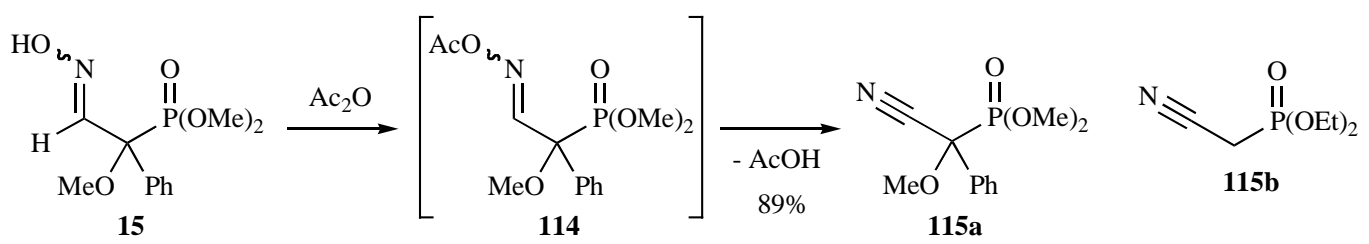

Scheme 39.

\subsubsection{O-Functionalization Reactions}

Functionalized $O$-tosyloximes 116, can be easily accomplished by simple reaction of phosphorated oximes derived from phosphonate $31(\mathrm{R}=\mathrm{OEt})$ or phosphine oxide $31(\mathrm{R}=\mathrm{Ph})$ with tosyl chloride in pyridine (Scheme $\mathbf{4 0}$ ). The synthesis of these phosphorylated tosyl ketoximes $\mathbf{1 1 6}$ has been applied to the asymmetric preparation of phosphorylated $2 \mathrm{H}$-azirines $\mathbf{1 1 7}$ and $\mathbf{1 1 8}$ through the modified Neber reaction $[57,58]$. The same approach has been applied to the synthesis of $2 H$-azirines $\mathbf{1 1 7}$ as building blocks for the preparation of oxazoles [59], and $\alpha$ - and $\beta$-aminophosphonates [14,35]. $p$ Tosyloximes 116 derived from phosphonates and phosphine oxides can also be used as synthons for the preparation of phosphorus substituted pyrazines 119 and $\mathbf{1 2 0}$ [60]. Treatment of $p$-tosyloximes derived from phosphonates $116(\mathrm{R}=\mathrm{OEt})$ with primary or secondary amines ( $\alpha$-methylbenzylamine, diethylamine or piperidine) at room temperature give pyrazines 119. Similarly, pyrazines 120 can be obtained from $p$-tosyloximes derived from phosphine oxides $\mathbf{1 1 6}$ $(\mathrm{R}=\mathrm{Ph})$ in the presence of piperidine (Scheme 40). The formation of these pyrazines suggests the dimerization of vinyl nitrene intermediates or unstable nitrile ylide dipoles, generated from oximes 116, followed by oxidation. In the case of pyrazines 120, loss of diphenyl phosphine oxide $\left(\mathrm{HPOPh}_{2}\right)$ takes place.

$O$-Functionalization reaction of fluoroalkyl ketoximes $\mathbf{1 2 1}$ for the preparation of fluoroalkyl $p$-toluenesulfonyl ketoximes $\mathbf{1 2 2}$ have been recently reported by our group [19]. For this purpose, $p$ - toluenesulfonyl chloride in the presence of a base such as sodium hydride was necessary for the tosylation of oximes 121 (Scheme 41). $O$-Functionalized oximes $\mathbf{1 2 2}$ have been applied to the stereoselective synthesis of fluoroalkyl substituted aziridine-2-phosphine oxides and phosphonates 123-125 by diastereoselective addition of methoxide, imidazole, benzenethiol, and Grignard reagents (Scheme 41).

\section{CONCLUSIONS}

The versatility and synthetic interest of functionalized $\beta$ hydroxyimino phosphorus derivatives are outlined. Most of the published strategies in the preparation of phosphine oxides, phosphonates or phosphonium salts containing an oxime moiety at the beta-position, refer to the carbon-nitrogen double bond construction or the carbon-phosphorus single bond formation reactions.

Condensation reaction of $\beta$-keto phosphorus substituted compounds with hydroxylamines has been so far the most employed strategy to the preparation of phosphorated oximes through carbonnitrogen double bond formation, while alkylation of phosphines and phosphites can be considered a remarkable synthetic procedure to achieve $\beta$-oximo phosphorus derivatives via a carbon-phosphorus single bond-forming process. Although the application of the hydrophosphinylation of $N$-protected $\alpha$-amino aldehydes has become a useful and versatile method for the synthesis of the very interesting $\alpha$-hydroxy- $\beta$-amino phosphonic acid derivatives, only a report has reported the nucleophilic addition of phosphorus reagents to

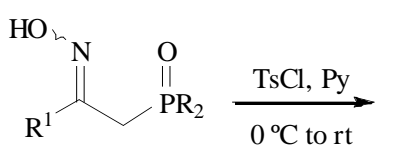

31

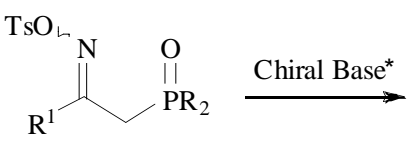

116

$$
\mathrm{R}_{2}^{2} \mathrm{NH}
$$

EtOH or $\mathrm{C}_{6} \mathrm{H}_{6}$, rt

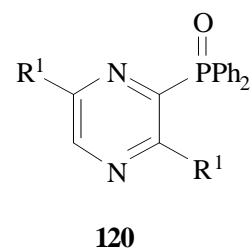

or
R<smiles></smiles>

117 or<smiles>[R]C1=N[C@@H]1[PH+](=O)[PH2+]</smiles><smiles>[R]c1nc(P(=O)(CCC)OCCC)c([R])nc1[PH](=O)OCC</smiles>

$\mathrm{O}$

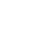

\begin{tabular}{|c|c|c|c|c|c|c|c|c|}
\hline 31 & $\mathbf{R}$ & $\mathbf{R}^{1}$ & 116 & Yield (\%) & $2 H$-Azirine & Yield (\%) & Pyrazine & Yield (\%) \\
\hline $31 \mathrm{a}$ & OEt & $\mathrm{Me}$ & $116 a$ & 73 & $117 a$ & 90 & 119a & 97 \\
\hline 31b & OEt & Et & $116 b$ & 70 & $117 b$ & 95 & $119 b$ & 98 \\
\hline $31 \mathrm{c}$ & OEt & $\mathrm{Ph}$ & $116 c$ & 35 & $117 \mathrm{c}$ & 69 & & \\
\hline 31d & $\mathrm{Ph}$ & $\mathrm{Me}$ & 116d & 61 & 118a & 96 & $120 \mathrm{a}$ & 70 \\
\hline $31 \mathrm{e}$ & $\mathrm{Ph}$ & Et & $116 \mathrm{e}$ & 58 & $118 b$ & 95 & $120 \mathrm{~b}$ & 68 \\
\hline
\end{tabular}

Scheme 40. 


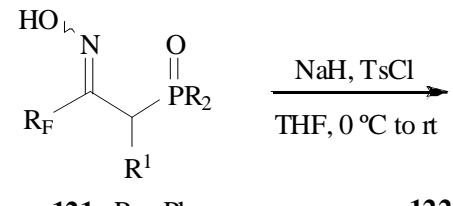

121a $\mathrm{R}=\mathrm{Ph}$

121b $\mathrm{R}=\mathrm{OEt}$

$$
\begin{aligned}
& \mathrm{R}^{1}=\mathrm{H}, \mathrm{Me} \\
& \mathrm{R}_{\mathrm{F}}=\mathrm{CF}_{3}, \mathrm{CHF}_{2}, \mathrm{C}_{2} \mathrm{~F}_{5}, \mathrm{C}_{7} \mathrm{~F}_{15}
\end{aligned}
$$<smiles>[R]C(=NO)C([R])[R2](=O)O[Na]</smiles>

122a $R_{F}=C F_{3}, R=P h, R^{1}=H 84 \%$

122b $\mathrm{R}_{\mathrm{F}}=\mathrm{CHF}_{2}, \mathrm{R}=\mathrm{Ph}, \mathrm{R}^{1}=\mathrm{H} 59 \%$

122c $\mathrm{R}_{\mathrm{F}}=\mathrm{C}_{7} \mathrm{~F}_{15}, \mathrm{R}=\mathrm{Ph}, \mathrm{R}^{1}=\mathrm{H} 64 \%$

122d $\mathrm{R}_{\mathrm{F}}=\mathrm{CF}_{3}, \mathrm{R}=\mathrm{OEt}, \mathrm{R}^{1}=\mathrm{H} 48 \%$

122e $R_{F}=C_{2} F_{5}, R=O E t, R^{1}=H 43 \%$

122f $\mathrm{R}_{\mathrm{F}}=\mathrm{CF}_{3}, \mathrm{R}=\mathrm{OEt}, \mathrm{R}^{1}=\mathrm{Me} 45 \%$

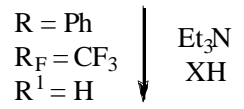

124b $\mathrm{X}=\mathrm{SPh} 69 \%$

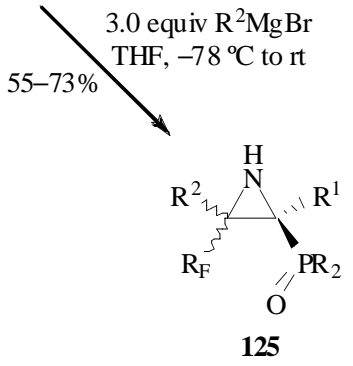

$\mathrm{R}^{2}=\mathrm{Me}, \mathrm{Et}, \mathrm{Ph}, \mathrm{Bn}$, Allyl
Scheme 41.

keto-oximes for the synthesis of $\alpha$-hydroxy- $\beta$-oximo phosphine oxides in moderate yield. The use of the enantioselective metalcatalysed version of this reaction could offer a very efficient method for the preparation of optically pure $\alpha$-hydroxy- $\beta$-oximo phosphonic acid derivatives.

Characteristic reactions of the oxime function such as the oxidation or the reduction of these substrates have been reported. Therefore, these polyfunctional compounds can be used in the elaboration of complex molecules such as natural products epothilones $\mathrm{A}$ and $\mathrm{B}$, phosphonated dihydroisoxazole nucleosides, $1 \beta$-methylcarbapenem antibiotics and $\beta$-amino phosphorus derivatives. Moreover, the presence of phosphorus functional groups confers an additional preparative interest to these substrates because they can be used for the construction of selective $\mathrm{C}-\mathrm{C}$ double bonds by means of the Wittig reaction or related processes. These bifunctional $\beta$-hydroxyimino phosphorus derivatives are excellent synthetic intermediates in preparative organic chemistry and in medicinal chemistry for the synthesis of a wide number of acyclic and heterocyclic compounds, some of them presenting biological activity. The use of enantioselective processes could use the synergy of both moieties (oximo and phosphorated groups) and open a new and efficient way for the preparation of optically pure functionalized organophosphorus derivatives and biologically active compounds.

\section{ACKNOWLEDGEMENT}

The present work was financially supported by the Dirección General de Investigación del Ministerio de Ciencia e Innovación (DGI, CTQ2009-12156 BQU), the Departamento de Educación, Universidades e Investigación del Gobierno Vasco (GV, Vitoria, IT-422-10) and by the Universidad del País Vasco (UPV/EHU) (GIU 09/57). Vicario, J. thanks the Ministerio de Ciencia e Innovación (Madrid) for a Ramón y Cajal contract.

\section{REFERENCES}

[1] Bicknell, A. J.; Burton, G.; Elder, J. S. Novel phosphorane and phosphonate synthons for vinyl glycines. Tetrahedron Lett., 1988, 29, 3361-3364.
[2] (a) Kaiser, A.; Wiegrebe, W. 1,3-Diphenylpropan-1,3-diamines IX. Reaction of $\alpha$-chlorooxime ethers with $\alpha$-lithiobenzylamines. Monatsh. Chem., 1996, 127, 763-774. (b) Hassner, A.; Alexanian, V. Synthesis of some 1-azirines from $\alpha$-bromo ketoximes via oxazaphospholines. J. Org. Chem., 1979, 44, 3861-3864. (c) Gaudiano, G.; Mondelli, R.; Ponti, P. P.; Ticozzi, C.; UmaniRonchi, A. Base-induced cyclization of 2-oximinophosphonium salts. Synthesis and spectroscopic properties of 1,2,5-oxazaphospho(V)ol-2-ines. $J$. Org. Chem., 1968, 33, 4431-4438.

[3] Noguchi, H.; Aoyama, T.; Shioiri, T. Total synthesis and absolute configuration of radiosumin, a strong trypsin inhibitor from the blue-green alga plectonema radiosum. Heterocycles, 2002, 58, 471-504. (b) Maier, L.; Diel, P. J. Organic phosphorus compounds 105 . Synthesis and properties of 2-amino-2arylethylphosphonic acids and derivatives. Phosphorus Sulfur Silicon Relat. Elem., 1995, 107, 245-255.

[4] Palacios, F.; Ochoa de Retana, A. M.; Gil, J. I. unpublished results.

[5] Boger, D. L.; Corbett, W. L.; Wiggins, J. M. Room temperature, endospecific 1-aza-1,3-butadiene Diels-Alder reactions: acceleration of the LU$\mathrm{MO}_{\text {diene }}$-controlled [4+2] cycloaddition reactions through noncomplementary azadiene substitution. J. Org. Chem., 1990, 55, 2999-3000.

[6] Masaki, M.; Fukui, K.; Ohta, M. The reaction of $\alpha$-halo oximes with triphenylphosphine. Formation of imidoyl bromide and of oximinophosphonium salts by a novel catalytic effect of bases. J. Org. Chem., 1967, 32, 3564-3568.

[7] Goerlich, J. R.; Schmutzler, R. $\alpha$-Hydroxyphosphinoxide und -sulfide durch addition von dimethylphosphinoxid bzw. -sulfid and aldehyde und ketone. Phosphorus Sulfur Silicon Relat. Elem., 1995, 101, 213-220.

[8] (a) Krueger, W. E.; Miller, E. J.; Rheingold, A. L. The crystal and molecular structure of 2-dimethoxyphosphinyl-2-methoxy-2-phenylacetaldehyde oxime. A single-crystal x-ray diffraction study. Phosphorus Sulfur, 1985, 24, 251-257. (b) Krueger, W. E.; McLean, M. B.; Rizwaniuk, A.; Maloney, J. R.; Behelfer, G. L.; Boland, B. E. Additions of trialkyl phosphites to nitroalkenes. J. Org. Chem., 1978, 43, 2877-2879. (c) Krueger, W. E.; Maloney, J. R. Addition of trimethyl phosphite to $\beta$-nitrostyrene. J. Org. Chem., 1973, 38, 4208-4209.

[9] Russell, G. A.; Yao, C. F. Reactions of ethyl phosphites with $\beta$-nitrostyrenes. The role of nitrosoalkenes as intermediates. J. Org. Chem., 1992, 57, 65086513. (b) Russell, G. A.; Yao, C. F.; Tashtoush, H. I.; Russell, J. E.; Dedolph, D. F. Addition, substitution, and deoxygenation reactions of $\alpha$ phenyl- $\beta$-nitrostyrenes with the anions of thiols and diethyl phosphite: formation of indoles by reaction with ethyl phosphites. J. Org. Chem., 1991, 56, 663-669.

[10] Tronchet, J. M. J.; Bonenfant, A. P.; Pallie, K. D.; Habashi, F. Derivatives of enoxe- and ynosephosphonates and related compounds. Helv. Chim. Acta, 1979, 62, 1622-1625. 
[11] Kao, K.; Yang, C.; Liu, J.; Lin, W.; Fang, H.; Yao, C.; Chen, K. One-pot synthesis of the hydroximoyl chlorides and [3.3.0] bicyclic compounds from the reactions of $\beta$-nitrostyrenes with stabilized nucleophiles. Tetrahedron, 1998, 54, 13997-14014.

[12] (a) Lee, K. S.; Kang, Y. K.; Yoo, K. H.; Kim, D. C.; Shin, K. J.; Paik, Y.; Kim, D. J. Novel $1 \beta$-methylcarbapenems with isoxazoloethenyl moieties containing carboxylic acid sodium salt. Bioorg. Med. Chem. Lett., 2005, 15, 231-234. (b) Jones, R. C. F.; Bhalay, G.; Carter, P. A. An isoxazole route to unsaturated $\alpha$-alkoxycarbonyl- $\beta$-diketones. J. Chem. Soc., Perkin Trans. 1, 1993, 1715-1716. (c) Nkusi, G.; Neidlein, R. Convenient synthesis of diethyl 3-methylisoxazoline and isoxazolephosphonates, potent synthons to biological active compounds. J. Prakt. Chem. /Chem. -Ztg., 1992, 334, 278280. (d) Tsuge, O.; Kanemasa, S.; Suga, H.; Nakagawa, N. Synthesis of (diethoxyphosphoryl)acetonitrile oxide and its cycloaddition to olefins. Synthetic applications to 3,5-disubstituted 2-isoxazolines. Bull. Chem. Soc. Jpn., 1987, 60, 2463-2473. (e) Tsuge, O.; Kanemasa, S.; Suga, H. Synthesis of a new phosphorus-functionalized nitrile oxide, $\alpha$-(diethylphosphono)acetonitrile oxide, and cycloaddition leading to 3-(diethylphosphonomethyl)- $\Delta^{2}$ isoxazolines. Chem. Lett., 1986, 183-186. (f) Gryszkiewicz-Trochimowski, E.; Chmelevsky, A. Sur la synthèse de (formylméthyl) phosphonate de diméthyle. Bull. Soc. Chim. Fr., 1966, 2043-2044.

[13] Livant, P.; Cocivera, M. Nucleophilic addition and subsequent oximeassisted ester hydrolysis of diethyl $\beta$-ketopropylphosphonate. J. Org. Chem., 1978, 43, 3011-3015

[14] Palacios, F.; Aparicio, D.; Ochoa de Retana, A. M.; de los Santos, J. M.; Gil, J. I.; López de Munain, R. Asymmetric synthesis of $2 \mathrm{H}$-aziridine phosphonates, and $\alpha$ - or $\beta$-aminophosphonates from enantiomerically enriched $2 \mathrm{H}$ azirines. Tetrahedron: Asymmetry, 2003, 14, 689-700.

[15] Whitten, J. P.; Baron, B. M.; McDonald, I. A. Competitive NMDA receptor antagonists: $(R)$-4-oxo-5-phosphononorvaline structure-activity relationships. Bioorg. Med. Chem. Lett., 1993, 3, 23-26.

[16] Aboujaoude, E. E.; Collignon, N. A simple synthesis of dialkyl 1formylalkanephosphonates. Synthesis, 1983, 634-636.

[17] Bode, J. W.; Carreira, E. M. Stereoselective syntheses of epothilones A and B via nitrile oxide cycloadditions and related studies. J. Org. Chem., 2001, 66, 6410-6424.

[18] Collington, E. W.; Knight, J. G.; Wallis, C. J.; Warren, S. Regiospecific synthesis of $(E)$ unsaturated 3,5-dialkyl-isoxazoles and derived leukotriene analogues using phosphine oxides. Tetrahedron Lett., 1989, 30, 877-880.

[19] Palacios, F.; Ochoa de Retana, A. M.; Alonso, J. M. Regioselective synthesis of fluoroalkylated $\beta$-aminophosphorus derivatives and aziridines from phosphorylated oximes and nucleophilic reagents. J. Org. Chem., 2006, 71, 61416148

[20] Balthazor, T. M. Phosphindolin-3-one. A useful intermediate for phosphindole synthesis. J. Org. Chem., 1980, 45, 2519-2522.

[21] Feistauer, H.; Neidlein, R. 135. Synthesen, chemische reaktionen und NMRspektroskopische untersuchungen substituierter phosphonopyruvate. Helv. Chim. Acta, 1995, 78, 1806-1822.

[22] Gonzalez-Nogal, A. M.; Cuadrado, P.; Sarmentero, M. A. Regio- and stereospecific cleavage of stannyloxiranes with lithium diphenylphosphide. Eur. J. Org. Chem., 2009, 850-859.

[23] Mathey, F.; Lampin, J. P.; Thavard, D. Synthèse de nouveaux phospholènes et phospholes avec substituants fonctionnels sur le phosphore. Can. J. Chem., 1976, 54, 2402-2410.

[24] Lampin, J. -P.; Eberhard, L.; Mathey, F.; Longeau, M. Métallation des phospholènes. Compléments expérimentaux. Bull. Soc. Chim. Fr., 1972, 3494-3502.

[25] Kouno, R.; Tsubota, T.; Okauchi, T.; Minami, T. Synthesis and synthetic applications of $\alpha$-formylvinylphosphonates. Facile synthesis of phosphonosubstituted heterocyclic compounds. J. Org. Chem., 2000, 65, 4326-4332.

[26] Whitesell, M. A.; Kyba, E. P. Addition of amine nucleophiles to diphosphorylalkynes. The chemistry of the derived enamines. Tetrahedron Lett., 1983, 24, 1679-1682.

[27] (a) Palacios, F.; Aparicio, D.; de los Santos, J. M.; Rodríguez, E. An improved and effective method for the preparation of $\alpha, \beta$-unsaturated oximes and isoxazole derivatives. Tetrahedron, 1998, 54, 599-614. (b) Palacios, F.; Aparicio, D.; de los Santos, J. M.; Rodríguez, E. An improved and general method for the synthesis of $\alpha, \beta$-unsaturated oximes from phosphine oxide allenes. Tetrahedron Lett., 1996, 37, 1289-1292.

[28] Bestmann, H. J.; Kunstmann, R. Reaktionen von phosphinalkylenen mit nitriloxiden. Eine neue synthesemöglichkeit für azirine, ketenimine und $\alpha, \beta$ ungesättigte oxime. Chem. Ber., 1969, 102, 1816-1832. (b) Bestmann, H. J.; Denzel, Th.; Kunstmann, R.; Lengyel, J. Additional reactions of triphenylphosphinecyclopropylidene. Tetrahedron Lett., 1968, 9, 2895-2898.

[29] (a) Abell, A. D.; Edmonds, M. K. The Wittig and related reactions. Organophosphorus Reagents, 2004, 99-127. (b) Bestmann, H. J.; Hellwinkel, D.;
Krebs, A.; Pommer, H.; Schoellkopf, U.; Thieme, P. C.; Vostrowsky, O.; Wilke, J. Topics in Current Chemistry, Vol. 109; Wittig Chemistry, 1983.

[30] Boger, D. L.; Corbett, W. L. $4 \pi$ Participation of 1-aza-1,3-butadienes in [4+2] cycloaddition reactions: intramolecular Diels-Alder reactions of $\alpha, \beta$ unsaturated $N$-sulfonylimines. J. Org. Chem., 1993, 58, 2068-2074.

[31] Boger, D. L.; Corbett, W. L.; Curran, T. T.; Kasper, A. M. Inverse electron demand Diels-Alder reactions of $N$-sulfonyl $\alpha, \beta$-unsaturated imines: a general approach to implementation of the $4 \pi$ participation of 1-aza-1,3butadienes in Diels-Alder reactions. J. Am. Chem. Soc., 1991, 113, 17131729 .

[32] Wensbo, D.; Gronowtiz, S. Indole-3-pyruvic acid oxime ethers and thieno analogues by Heck cyclization. Application to the synthesis of thiatryptophans. Tetrahedron, 1996, 52, 14975-14988.

[33] Noguchi, H.; Aoyama, T.; Shioiri, T. Determination of the absolute configuration and total synthesis of radiosumin, a trypsin inhibitor from a freshwater blue-green alga. Tetrahedron Lett., 1997, 38, 2883-2886.

[34] Roberts, J. L.; Chan, C. Asymmetric synthesis of differentially protected meso-2,6-diaminopimelic acid. Tetrahedron Lett., 2002, 43, 7679-7682.

[35] (a) Palacios, F.; Alonso, C.; de los Santos, J. M. Synthesis of $\beta$ aminophosphonates and -phosphinates. Chem. Rev., 2005, 105, 899-931. (b) Palacios, F.; Alonso, C.; de los Santos, J. M. $\beta$-Phosphono- and phosphinopeptides derived from $\beta$-amino-phosphonic and phosphinic acids Curr. Org. Chem., 2004, 8, 1481-1496.

[36] Liorber, B. G.; Pavlov, V. A.; Khamatova, Z. M. Reduction of phosphorylacetaldehyde oximes to phosphoryl hydroxylamines. Zh. Obshch. Khim. 1989, 59, 2634-2636; Chem. Abstr., 1990, 112, 158400.

[37] (a) Padwa, A.; Pearson, W. H. The Chemistry of Heterocyclic Compounds: Synthetic Applications of 1,3-Dipolar Cycloaddition Chemistry Toward Heterocycles and Natural Products, John Wiley \& Sons: New York, 2002, Vol 59. (b) Caramella, P.; Grünanger, P. In 1,3-Dipolar Cycloaddition Chemistry; Padwa, A., Ed.; John Wiley \& Sons: New York, 1984; Vol. 1, pp. 291 392.

[38] (a) Cremonesi, G.; Dalla Croce, P.; Fontana, F.; Fiorelli, C.; La Rosa, C Stereoselective synthesis of $\beta, \varepsilon$-dihydroxy- $\alpha$-amino acids by ring opening of 4,5-dihydroisoxazolyl derivatives. Tetrahedron: Asymmetry, 2008, 19, 28502855. (b) Furstner, A.; Fenster, M. D. B.; Fasching, B.; Godbout, C.; Radkowski, K. Toward the total synthesis of spirastrellolide A. part 2: conquest of the northern hemisphere. Angew. Chem., Int. Ed., 2006, 45, 5510-5515.

[39] Jäger, V.; Schwab, W; Buss, V. Model reactions for the stereo-controlled synthesis of aminopolyols; reduction of isoxazolines with free or protected hydroxy groups in position 4 or in side chains Angew. Chem., Int. Ed., 1981, 20,601-603

[40] Tsuge, O.; Kanemasa, S.; Suga, H. An entry to 5-(1-alkenyl)-3(2H)furanones through cycloaddition of phosphorus-functionalized nitrile oxide to acetylene alcohols. An effective synthesis of geiparvarin. Chem. Lett., 1987, 323-326.

[41] Tsuge, O.; Kanemasa, S.; Suga, H. Synthesis of 2-(1-phosphorylalkyl)- and 2-(1-alkenyl)furans through nitrile oxide cycloaddition route. Bull. Chem Soc. Jpn., 1988, 61, 2133-2146.

[42] Kanemasa, S.; Asai, Y.; Tanaka, J. Synthesis of substituted pyridines by cycloaddition route using nitrile oxides and homoallyl alcohols. Bull. Chem. Soc. Jpn., 1991, 64, 375-380.

[43] Kanemasa, S.; Nakagawa, N.; Suga, H.; Tsuge, O. Synthesis of 4-[(E)-1Alkenyl]-2-hydroxybutanolides and (Z)-4-alkylidene-2-butenolides through cycloadditions using a phosphorus-functionalized nitrile oxide. Bull. Chem. Soc. Jpn., 1989, 62, 171-179.

[44] Romeo, G.; Iannazzo, D.; Piperno, A.; Romeo, R.; Saglimbeni, M.; Chiacchio, M. A.; Balestrieri, E.; Macchi, B.; Mastino, A. Synthesis and biological evaluation of phosphonated dihydroisoxazole nucleosides. Bioorg. Med. Chem., 2006, 14, 3818-3824.

[45] Bode, J. W.; Carreira, E. M. Stereoselective syntheses of epothilones A and B via directed nitrile oxide cycloaddition. J. Am. Chem. Soc., 2001, 123, 3611-3612.

[46] Kanemasa, S.; Nishiuchi, M.; Kamimura, A.; Hori, K. First successful metal coordination control in 1,3-dipolar cycloadditions. High-rate acceleration and regio- and stereocontrol of nitrile oxide cycloadditions to the magnesium alkoxides of allylic and homoallylic alcohols. J. Am. Chem. Soc., 1994, 116 2324-2329.

[47] Lohse-Fraefel, N.; Carreira, E. M. A modular approach to polyketide building blocks: cycloadditions of nitrile oxides and homoallylic alcohols. Org. Lett., 2005, 7, 2011-2014.

[48] Gilchrist, T. L. Nitroso-alkenes and nitroso-alkynes. Chem. Soc. Rev., 1983, $12,53-73$

[49] (a) Tishkov, A. A.; Lesiv, A. V.; Khomutova, Y. A.; Strelenko, Y. A.; Nesterov, I. D.; Antipin, M. Y.; Ioffe, S. L.; Denmark, S. E. 2-Silyloxy-1,2 oxazines, a new type of acetals of conjugated nitroso alkenes. J. Org. Chem., 
2003, 68, 9477-9480. (b) Trewartha, G.; Burrows, J. N.; Barret, A. G. M. Glycosidation via conjugate addition of anomeric alkoxides to nitroalkenes and nitrosoalkenes. Tetrahedron Lett., 2005, 46, 3553-3556.

[50] Corsaro, A.; Chiacchio, U.; Pistara, V. Regeneration of carbonyl compounds from the corresponding oximes. Synthesis, 2001, 1903-1931.

[51] (a) Domingo, L. R.; Picher, M. T.; Arroyo, P. Towards an understanding of the polar Diels-Alder reactions of nitrosoalkenes with enamines: a theoretical study. Eur. J. Org. Chem., 2006, 2570-2580. (b) Gallos, J. K.; Sarli, V. C.; Massen, Z. S.; Varvogli, A. C.; Papadoyanni, C. Z.; Papaspyrou, S. D.; Argyropoulos, N. G. A new strategy for the stereoselective synthesis of unnatural $\alpha$-amino acids. Tetrahedron, 2005, 61, 565-574. (c) Wabnitz, T. C.; Saaby, S.; Jørgensen, K. A. The first catalytic inverse-electron demand hetero-DielsAlder reaction of nitroso alkenes using pyrrolidine as an organocatalyst. Org. Biomol. Chem., 2004, 2, 828-834. (d) Zimmer, R; Reissig, H. -U. Efficient synthesis of trifluoromethyl-substituted 5,6-dihydro- $4 H$-1,2-oxazines by the hetero-Diels-Alder reaction of 1,1,1-trifluoro-2-nitroso-2-propene and electron-rich olefins. J. Org. Chem., 1992, 57, 339-347.

[52] de los Santos, J. M.; Ignacio, R.; Aparicio, D.; Palacios, F. Michael addition of amine derivatives to conjugate phosphinyl and phosphonyl nitrosoalkenes. Preparation of $\alpha$-amino phosphine oxide and phosphonate derivatives. $J$. Org. Chem., 2007, 72, 5202-5206.

[53] de los Santos, J. M.; Ignacio, R.; Aparicio, D.; Palacios, F.; Ezpeleta, J. M. Reactions of conjugate phosphinyl- and phosphonyl-nitroso alkenes with enamines. Preparation of $N$-hydroxypyrrole derivatives. J. Org. Chem., 2009, 74, 3444-3448.

[54] Haelters, J. P.; Corbel, B.; Sturtz, G. Chloro-1 et chloro-3 methoxycarbonylhydrazono-2 propylphosphonates: reactifs d'alkylation d'enolates de cetones.
Acces a des phosphonates pyrroliques et a des $\beta, \varepsilon$ dicetophosphonates precurseurs de cyclopentenones. Phosphorus Sulfur Silicon Relat. Elem., 1989, 44, 53-74.

[55] (a) Palacios, F.; Ochoa de Retana, A. M.; Martínez de Marigorta, E.; de los Santos, J. M. Preparation, properties and synthetic applications of $2 \mathrm{H}$ azirines. A review. Org. Prep. Proced. Int., 2002, 34, 219-269. (b) Palacios, F.; Ochoa de Retana, A. M.; Martínez de Marigorta, E.; de los Santos, J. M. $2 \mathrm{H}$-azirines as synthetic tools in organic chemistry. Eur. J. Org. Chem., 2001, 2401-2414.

[56] Alonso, J. M. 2H-Azirinas Como Intermediarios Sintéticos Para La Preparación De Derivados Aminofosforados Acíclicos y Cíclicos. PhD Thesis, University of the Basque Country: Vitoria, 2005.

[57] Palacios, F.; Ochoa de Retana, A. M.; Gil, J. I. Easy and efficient synthesis of enantiomerically enriched $2 \mathrm{H}$-azirines derived from phosphonates. Tetrahedron Lett., 2000, 41, 5363-5366.

[58] Palacios, F.; Ochoa de Retana, A. M.; Gil, J. I.; Ezpeleta, J. M. Simple asymmetric synthesis of $2 \mathrm{H}$-azirines derived from phosphine oxides. J. Org. Chem., 2000, 65, 3213-3217.

[59] Palacios, F.; Aparicio, D.; Ochoa de Retana, A. M.; de los Santos, J. M.; Gil, J. I.; Alonso, J. M. Asymmetric synthesis of $2 \mathrm{H}$-azirines derived from phosphine oxides using solid-supported amines. Ring opening of azirines with carboxylic acids. J. Org. Chem., 2002, 67, 7283-7288.

[60] Palacios, F.; Ochoa de Retana, A. M.; Gil, J. I.; López de Munain, R. Synthesis of pyrazine-phosphonates and -phosphine oxides from $2 \mathrm{H}$-azirines or oximes. Org. Lett., 2002, 4, 2405-2408. 